\title{
Horizontal versus Vertical Interdependence in Multinational Activity
}

\author{
HARALD BADINGER \\ PETER EGGER
}

CESIFO WORKING PAPER NO. 2327

CATEGORY 9: INDUSTRIAL ORGANISATION

JUNE 2008

\footnotetext{
An electronic version of the paper may be downloaded

- from the SSRN website:

www.SSRN.com

- from the RePEc website:

- from the CESifo website:

www.RePEc.org

www.CESifo-group.org/wp
} 


\title{
Horizontal versus Vertical Interdependence in Multinational Activity
}

\begin{abstract}
Recent research in international economics highlights the role of interdependencies of investment decisions and sales of multinational firms. Previous work focused on and provided evidence for aggregate flows or stocks of foreign direct investment, showing that interdependence declines in geographical distance among host countries. This could be interpreted as implicit evidence for export-platform foreign direct investment - an activity which creates a complementary relationship between (potential) host markets through final goods exports of foreign subsidiaries to third countries. This paper sheds light on interdependencies that are brought about by (horizontal) trade in final goods and (vertical) trade in intermediate goods (within and between host countries). For this, we use a panel data set of U.S. foreign affiliate sales to 16 developed countries in 7 industries over the period 1983-2000. As one of the first studies on that matter, we explicitly distinguish between horizontal and vertical interdependence in MNE activity and allow for both market size (demand) related as well as remainder linkage effects. The latter are captured by a second order spatial regressive error process. Overall, there is evidence for mainly vertical as opposed to horizontal interdependence and, hence, mainly vertical motives of multinational activity.
\end{abstract}

JEL Code: C21, C23, F21, F23.

Keywords: multinational firms, foreign affiliate sales, spatial econometrics, generalized method of moments estimation, panel data analysis.

\author{
Harald Badinger* \\ Department of Economics \\ Vienna University of Economics and \\ Business Administration \\ Althanstrasse 39 - 45 \\ 1090 Vienna \\ Austria \\ harald.badinger@wu-wien.ac.at
}

\author{
Peter Egger \\ Ifo Institute for Economic Research at \\ the University of Munich \\ Poschingerstrasse 5 \\ 81679 Munich \\ Germany \\ egger@ifo.de
}

May 2008

*This paper was written during my stay as Erwin-Schrödinger Research Fellow at the Center for Economic Studies (CES), University of Munich. Financial support by the Austrian Science Fund (FWF) is gratefully acknowledged. 
“... both export-platform and complex-vertical motivations imply that FDI

decisions are multilateral in nature ..."

(Blonigen, Davies, Waddell, Naughton, 2007, p. 1304)

\section{Introduction}

A new strand of literature on the determinants of multinational enterprise (MNE) activity in general and foreign direct investment (FDI) in particular highlights the interdependence of MNEs' investments and production across countries. Taking this interdependence into account seems relevant for two reasons. First, empirical work on the determinants of MNE activity mainly uses bilateral data and, in general equilibrium, bilateral flows depend not only on bilateral but also on third-country determinants. ${ }^{1}$ Second, evidence on the relative importance of alternative channels of interdependence-e.g., trade in final goods versus trade in intermediates-is informative about the relevance of different motives of MNE activity.

Theoretical work establishes interdependence across markets explicitly through the modeling of complex integration strategies of multinational enterprises (MNEs) in more than two countries (see Yeaple, 2003; Ekholm, Forslid, and Markusen, 2007; Grossman, Helpman, and Szeidl, 2007). There, integration strategies of multinationals are complex already by the number of opportunities for locating production facilities and exporting goods bilaterally. Two-country models of MNEs served to formalize stylized modes of MNE activity: horizontal and vertical MNE organization. A horizontal MNE produces the same good in either country and does not engage in final goods trade (see Markusen, 1984; Markusen and Venables, 2000); a vertical MNE fully disentangles headquarters services from final goods production, where the latter is located in the low-wage country with a comparative advantage in goods production (see Helpman, 1984; Helpman and Krugman, 1985). With more than two countries, complex MNEs arise, which are hybrid forms of horizontal and vertical MNEs. They serve a sub-set of potential host countries through local foreign affiliates and others via final goods trade from an export-platform subsidiary in a third host country (see Ekholm, Forslid, and Markusen, 2007) or even from a production site which is attached to the headquarters in the parent country (see Egger, Egger, and Ryan, 2007). The main channel of interdependence in the aforementioned work is demand for final goods: on the one hand,

\footnotetext{
${ }^{1}$ The role of bilateral as well as third-country variables is well-established in the literature on the determinants of bilateral trade flows in so-called gravity models (see Eaton and Kortum, 2002; Anderson and van Wincoop, 2003). However, while interdependence may be treated in a closed form in gravity models for goods flows, current models of both MNE activity and trade only deliver reduced-form specifications. Accordingly, our contribution belongs to the latter type of research.
} 
foreign affiliate sales (FAS) to a potential host country may decline if its neighbors grow ceteris paribus, because this increases the home market and size of other firms' subsidiaries there; on the other hand, FAS to that country may grow, if subsidiaries there are used as a platform to serve consumers in a neighboring country as well. This form of interdependence across host markets roots in final-goods-demand-linkages across markets.

Another strand of theoretical work emphasizes the role of vertically organized production networks within MNEs (see Helpman, 1985; Markusen, 2002, ch. 7; Grossman, Helpman, and Szeidl, 2007). Such networks establish an additional layer of interdependence through intrafirm intermediate goods demand rather than inter-firm final goods demand. ${ }^{2}$ The main mechanism at work there is that growing demand for an MNE's final goods creates demand for intermediate goods in all (relevant) subsidiaries within a firm.

An interesting feature of these two strands of theoretical work is that they provide hypotheses about two channels of interdependence across host markets: one related to trade in final goods and the other one associated with trade in intermediate goods.

Previous empirical work mainly considered final-goods-demand-related interdependence across host countries (see Baltagi, Egger, and Pfaffermayr, 2007; Blonigen, Davies, Waddell, and Naughton, 2007) and identified a positive impact of third-country market size ('market potential'). Moreover, associated work found interdependencies with respect to both observable and unobservable variables captured by the disturbances in the empirical model (see Baltagi, Egger, and Pfaffermayr, 2007; Blonigen, Davies, Waddell, and Naughton, 2007). Overall, evidence has been interpreted to point to the activity of complex MNEs in general and to export-platform activity in particular.

The goal of this paper is to explicitly disentangle vertical and horizontal modes of interdependence in an empirical panel data model of the determinants of U.S. FAS in 16 European countries. Sales of U.S. MNEs' foreign affiliates in these countries depend on each other through final and intermediate goods demand relationships, but they should be relatively independent of other (Asian or American) host markets. We use OECD input-output and trade data to construct measures of horizontal (final-goods-demand-related) and vertical interdependence (related to intermediate goods demand).

\footnotetext{
2 In Helpman (1985), Markusen (2002, ch. 7), and Grossman, Helpman, and Szeidl (2007), intermediate goods demand is strictly within firms. However, a similar type of complementarities across host markets may arise with arms-length (i.e., outside the firm) trade in intermediate goods as in Bergstrand and Egger (2008).
} 
The empirical analysis allows for both horizontal and vertical interdependence in market size (demand) as well as unobserved variables. The latter form of interdependence is captured by the error term and modeled using a second order 'spatial' regressive error process. As for the estimation approach, we consider a framework suitable for the analysis of cross-sectional interdependence of the units of observation. We adopt a generalized moments (GM) approach for 'spatially dependent' data in error component models introduced by Kapoor, Kelejian, and Prucha (2007). To allow for two channels of interdependence simultaneously-a horizontal and a vertical one- the present paper relies on an extension of existing estimation techniques for panel data models of 'spatial' interdependence which account for only a single channel of interdependence. ${ }^{3}$ In particular, we base our empirical analysis on the generalized moments (GM) estimator for higher order spatial autoregressive processes with panel data error component models in Badinger and Egger (2008).

Overall, our findings point to a dominance of vertical linkage effects and thus vertical motives of MNE activity. In light of the fact that our sample comprises FAS to a set of fairly homogenous, highly developed host countries, this is a particularly strong result. Furthermore, it is consistent with evidence about intermediate goods trade flows in Bergstrand and Egger (2008) and Jabbour (2008), who find that the lion's share of outsourcing and cross-border flows of intermediate goods occurs among the developed countries.

The remainder of the paper is organized as follows. The next section lays out an empirical model of foreign affiliate sales and distinguishes between the horizontal and vertical channel of interdependence. The Appendix elaborates on the GM estimation procedure for a second order spatial autoregressive model in a panel data error components model. Section III constructs measures of horizontal and vertical relationships, describes the data in use, summarizes the estimation results, and provides a sensitivity analysis. Section IV concludes with a summary of the most important findings.

\footnotetext{
${ }^{3}$ These models are referred to as ones of spatial interdependence since they originate from applications in geography, where interdependence literally occurs in space. In general, 'space' can be non-geographical, as will often be the case in economic applications. Existing panel data models for spatial dependence are based on first-order interdependence (spatially autoregressive residuals, SAR1). One of the novelties of this paper is to derive moment conditions that allow for second-order interdependence to capture horizontal and vertical interdependence of FAS simultaneously.
} 


\section{The conceptual framework: Horizontal versus vertical interdependence in foreign affiliate sales}

Models of MNE activity provide a rationale for direct interdependence in terms of observable variables across host markets along two lines, demand for final goods produced in the same industry (horizontal interdependence) and demand for intermediate goods (vertical interdependence). Denote the logarithm of foreign affiliate sales of all MNEs of a specific parent country (in our case, the U.S.) in industry $i$ to host country $j$ in year $t$ by $y_{i j, t}$. The total number of industries, host country, and years in the sample is given by $I, J$, and $T$, respectively.

It is useful to apply matrix notation for the exposition of the empirical model. Specifically, denote the $I J \times 1$ vector of bilateral foreign affiliate sales across all industries and host countries in year $t$ by $\mathbf{y}_{t}{ }^{4}$ The $I J \times K$ matrix $\mathbf{X}_{t}$ contains the observations of all $K$ explanatory variables (including a constant) in year $t$, and $\boldsymbol{\beta}$ is the corresponding $K \times 1$ vector of parameters. According to the discussion above, weighted foreign market size (or market potential) captures one reason for horizontal or even vertical interdependence and should be included in the empirical model (a more precise definition of this variable will be given below). However, we do not expect market potential to capture third-country effects in a comprehensive way. Other relevant third-country effects transmitted through horizontal or vertical relationships could result from (differences in) legal, institutional, cultural, or technological characteristics of host countries, which are hard to measure by observable variables. As usual in econometric models, we capture all such variables by a disturbance term. Let us denote the latter by the $I J \times 1$ vector $\mathbf{u}_{t}$. However, unlike previous studies on MNE activity, we allow the variables captured in the disturbance term to exhibit a horizontal as well as vertical cross-sectional dependence structure, similar to market potential. This leads to a second-order spatial regressive error process. Taking stock, we may characterize the empirical model for a single time period $t$ as follows:

$$
\mathbf{y}_{t}=\mathbf{X}_{t} \boldsymbol{\beta}+\mathbf{u}_{t} \quad \text { with } \quad \mathbf{u}_{t}=\left(\rho_{\mathrm{H}} \mathbf{H}+\rho_{\mathrm{V}} \mathbf{V}\right) \mathbf{u}_{t}+\boldsymbol{\mu}+\boldsymbol{\omega}_{t}
$$

where $\mathbf{H}$ and $\mathbf{V}$ are time-invariant $I J \times I J$ matrices reflecting the structure of horizontal and vertical interdependence. As will be outlined in more detail below, $\mathbf{H}$ and $\mathbf{V}$ will be constructed from bilateral trade and input-output data. The strength of horizontal and vertical

\footnotetext{
${ }^{4}$ We adopt the standard convention to refer to vectors and matrices by acronyms in boldface.
} 
interdependence is measured by the parameters $\rho_{\mathrm{H}}$ and $\rho_{\mathrm{V}}$, respectively. ${ }^{5}$ Finally, as is standard in the panel data error components literature, the $I J \times 1$ vector $\mu$ contains timeinvariant, industry-and-country-specific random effects, whereas the $I J \times 1$ vector $\boldsymbol{\omega}_{t}$ includes industry-and-country-specific, time-variant remainder disturbances. We may think of the latter two terms as catch-all vectors of time-variant and time-invariant variables affecting FAS, which are orthogonal to $\mathbf{X}_{t}, \mathbf{H}$, and $\mathbf{V}$.

The process of $\mathbf{u}_{t}$ in (1) can be re-written as $\mathbf{u}_{t}=\left(\mathbf{I}-\rho_{\mathrm{H}} \mathbf{H}+\rho_{\mathrm{V}} \mathbf{V}\right)^{-1}\left(\boldsymbol{\mu}+\boldsymbol{\omega}_{t}\right)$, where $\mathbf{I}$ denotes an $I J \times I J$ identity matrix. Obviously, this creates horizontal interdependence (through $\mathbf{H}$ ) and vertical interdependence (through $\mathbf{V}$ ) in $\mathbf{u}_{t}$ across all host country and industry pairs. Existing estimators for models of 'spatial' interdependence with panel data (e.g., Kapoor, Kelejian, and Prucha, 2007) rely upon a single channel of interdependence of the form $\mathbf{u}_{t}=(\mathbf{I}-\rho \mathbf{W})^{-1}\left(\boldsymbol{\mu}+\boldsymbol{\omega}_{t}\right)$ and would not allow to disentangle the horizontal $\left(\rho_{\mathrm{H}} \mathbf{H}\right)$ and the vertical dimension $\left(\rho_{\mathrm{V}} \mathbf{V}\right)$ of the process. We derive the moment conditions for a generalized method of moments estimator of $\rho_{\mathrm{H}}$ and $\rho_{\mathrm{V}}$ with panel data in Appendix A. ${ }^{6}$

Overall, model (1) allows for two channels through which horizontal and vertical interdependence materialize: in variables contained $\mathbf{X}_{t}$ such as vertical or horizontal market potential variables (see footnote 5); or in $\mathbf{u}_{t}$ through interdependence in FAS as captured by other, unobservable variables.

\section{Empirical analysis}

\section{Data}

Let us distinguish between three sets of data used in the subsequent empirical analysis: first, data on the dependent variable; second, data used to construct the elements of the matrices of

\footnotetext{
${ }^{5}$ Use the symbol $\mathbf{d}_{\mathrm{t}}$ to denote the vector of demand in all countries and industries for year $t$. Then, in analogy to interdependence in the disturbances we may express horizontal and vertical market potentials as $\mathbf{H d}_{t}$ and $\mathbf{V} \mathbf{d}_{t}$, respectively.

${ }^{6}$ The econometrics literature on spatial interdependence relies on maximum likelihood (Anselin, 1988; Lee, 2004) or generalized moments estimation (Kelejian and Prucha, 1999; Kapoor, Kelejian, and Prucha, 2007). Generalized moments estimation seems advantageous for various reasons. In any case, large data-sets with more than a single channel of interdependence would preclude the application of maximum likelihood estimators.
} 
horizontal and vertical interdependence, $\mathbf{H}$ and $\mathbf{V}$; third, explanatory variables to determine annual FAS at the industry and country-pair level as collected in $\mathbf{X}_{t}$.

\section{The dependent variable: Foreign affiliate sales (FAS)}

We use FAS of the United States as published by the Bureau of Economic Analysis. To ensure as much homogeneity across host countries with regard to political and institutional settings as possible in order to avoid omitted variables bias, we confine the analysis to a set of 16 European host countries and seven industries over the period 1983 to 2000. Appendix B provides a detailed description of the data and sample composition. The industry level of aggregation is dictated by the dependent variable (FAS). The focus on a set of Western European countries is motivated by their homogeneity with regard to relative factor endowments, the availability and quality of data on the explanatory variables, and the fact that U.S. MNEs much less likely trade off location and production decisions between Europe and other continents rather than within Europe.

Previous findings suggest that our focus on a set of fairly homogeneous, highly developed host countries should entail a relatively stronger presence of horizontal MNEs than in a broader sample including also less developed economies. In other words, evidence on the presence of vertical motives of MNEs in the present sample would be suggestive of their even more important role on a world-wide basis.

\section{Elements of the $\mathrm{H}$ and $\mathrm{V}$ matrices of interdependence}

The elements of both the horizontal interdependence matrix $\mathbf{H}$ and the vertical interdependence matrix $\mathbf{V}$ are based upon information from OECD’s Input-Output Database and the STAN Bilateral Trade Database. In particular, the entries of $\mathbf{H}$ reflect bilateral final goods trade flows across host countries of U.S. MNEs within an industry. Horizontal interdependence in bilateral FAS is hypothesized to be large where an element of $\mathbf{H}$ is relatively large, leading to a higher $\mathbf{H}$-related correlation in FAS between two host countries through demand (market potential) or unobservable variables. For instance, such an interdependence could be related to final goods trade within a particular industry among two host countries through U.S. export-platforms in either host country. Denote the typical element of $\mathbf{H}$ by $h_{i j, l m}$. The latter reflects final goods trade of country $i$ 's industry $j$ with country l's industry $m$, expressed as a share of gross output of country i's industry $j$. Horizontal relationships as defined above can only occur within an industry and across host countries. Consequently, $h_{i j, l m} \neq 0$ only for $i \neq l$ and $j=m$. 
Vertical interdependence occurs through input-output relationships within and across industrial boundaries-both within and across host countries. Analogously, vertical interdependence in FAS is hypothesized to be large where an element of $\mathbf{V}$ is relatively large. A typical element $v_{i j, m l}$ of the matrix $\mathbf{V}$ gives intermediate goods trade between country i's industry $j$ and country l's industry $m$, again expressed as a share of gross output. Potentially, all elements of $\mathbf{V}$ may take nonzero values.

Appendix B2 provides a detailed description of the construction of the interdependence matrices $\mathbf{V}$ and $\mathbf{H}$. In line with the literature on spatial econometrics, the main diagonal elements of $\mathbf{V}$ and $\mathbf{H}$ are set to zero. ${ }^{7}$ Furthermore, the elements of both $\mathbf{V}$ and $\mathbf{H}$ are normalized so that all entries in a row add up to unity (this is referred to as rownormalization).

\section{Explanatory variables collected in $\mathbf{X}_{t}$}

We use a large set of indicator variables but a small number of explanatory variables in $\mathbf{X}_{t}$. The indicator variables encompass a full set of country and industry dummies and wipe out all time-invariant country-specific (e.g., geographical, cultural, legal, institutional) and even industry-specific economic variables (such as relative factor endowments). This allows us to focus on the economic effects of a few industry-level covariates (varying across $i, j$, and $t$ ) and, in particular, on the issue of horizontal versus vertical interdependence in FAS. Among the covariates, we use gross output and apparent consumption (gross output minus exports plus imports) as two alternative measures of the size of domestic market size or demand, and export openness (nominal exports as a fraction of gross output) as well as import openness (nominal imports as a fraction of gross output) and labor productivity (value added per employee) as explanatory variables. ${ }^{8}$ Data source is the OECD STAN database.

Notice that bilateral FAS of U.S. MNEs in a particular industry constitute only a small share of a host country's total sales of that industry and, in turn, they are unlikely to be relevant

\footnotetext{
${ }^{7}$ Hence, we have to abstract from within-country-and-within-industry interdependence. Yet, this would be of minor interest in an international economics and industry-level study as ours.

${ }^{8}$ Other variables such as labor compensation per employee are also available. However, it turns out that the wage cost variable does not enter significantly different from zero due to its correlation with variables in the model (such as labor productivity or import openness). Hence, the suggested parsimonious model is preferable to the less parsimonious one. Also, using value added instead of gross output as a measure of demand does not change the results qualitatively.
} 
determinants of labor productivity or total trade in that country and industry. Hence, the set of explanatory variables in model (1) can be reasonably assumed to be exogenous.

The aforementioned theoretical work on the determinants of complex MNE activity delivers hypotheses about interdependence which mainly root in demand linkages - with regard to either final or intermediate goods. Therefore, two key variables of interest are related to foreign demand: one weighted by $\mathbf{H}$ and the other one weighted by $\mathbf{V}$. Collecting data on the level of demand for products from industry $i$ and country $j$ in year $t$ into the $I J \times 1$ vector $\mathbf{d}_{t}$, the horizontal and vertical demand linkage (or market potential) variables are $\mathbf{H d}_{t}$ and $\mathbf{V} \mathbf{d}_{t}$ respectively.

Descriptive statistics of the variables included in model (1) are summarized in Table B in the Appendix.

\section{Results}

With the explanatory variables at hand, the main specification of the model reads as follows:

$$
\begin{aligned}
& y_{i j, t}=\beta_{0}+\beta_{1} \text { Demand }_{i j, t}+\beta_{2} \text { Demand }_{i j, t}^{H}+\beta_{3} \text { Demand }_{i j, t}^{V}+\beta_{4} \text { Exports }_{i j, t} \\
& +\beta_{5} \text { Imports }_{i j, t}+\beta_{6}(\text { Value Added / Employment })_{i j, t}+\kappa_{i}+\lambda_{j}+u_{i j, t}
\end{aligned}
$$

where $y_{i j, t}$ is FAS in industry $i$ to host country $j$ in year $t$, and Demand $d_{i j, t}$ is measured either as gross output or apparent consumption and represents elements of $\mathbf{d}_{t}$. Demand ${ }_{i j, t}^{H}$ and Demand $_{i j, t}^{V}$ represent elements of $\mathbf{H d}_{t}$ and $\mathbf{V d} \mathbf{d}_{t}$, respectively. Exports ${ }_{i j, t}$ and Imports $_{i j, t}$ are measured as a share of gross output, and $u_{i j, t}$ is defined as in equation (1). Among the variables in equation (2), $y_{i j, t}$, Demand $_{i j, t}$, and (Value Added / Employment $)_{i j, t}$ enter in logarithmic form. $\kappa_{i}$ and $\lambda_{j}$ are host-country- and industry-specific fixed effects, respectively.

In vector form, equation (2) may be written for period $t$ as

$$
\mathbf{y}_{t}=\beta_{0} \mathbf{u}_{t}+\beta_{1} \mathbf{d}_{t}+\beta_{2} \mathbf{H d} \mathbf{d}_{t}+\beta_{3} \mathbf{V} \mathbf{d}_{t}+\beta_{4} \mathbf{x}_{t}+\beta_{5} \mathbf{m}_{t}+\beta_{6} \mathbf{a}_{t}+\mathbf{Z}_{t}^{\kappa} \mathbf{\kappa}+\mathbf{Z}_{t}^{\lambda} \lambda+\mathbf{u}_{t},
$$

where $\mathbf{t}_{t}, \mathbf{x}_{t}, \mathbf{m}_{t}$ and $\mathbf{a}_{t}$ indicate $I J \times 1$ vectors of ones and the observations on the variables Exports, Imports, and Value Added/Employment in period $t$, respectively. $\mathbf{Z}^{\kappa}$ and $\mathbf{Z}^{\lambda}$ are 
design matrices consisting of host-country- and industry-specific indicator variables, respectively, and $\boldsymbol{\kappa}$ and $\lambda$ are the corresponding fixed effect parameter vectors. By assumption, neither $\mathbf{Z}^{\kappa}$ and $\mathbf{Z}^{\lambda}$ nor $\boldsymbol{\kappa}$ and $\boldsymbol{\lambda}$ vary over time. All variables denoted by lowercase letters with subscript $t$ in equation (3) are $I J \times 1$ vectors, $\mathbf{Z}^{\kappa}$ is an $I J \times I$ matrix and $\mathbf{Z}^{\lambda}$ is of dimension $I J \times J$, $\mathrm{\kappa}$ is an $I \times 1$ vector, and $\lambda$ is of dimension $J \times 1$. In terms of equation (1), $\quad \mathbf{X}_{t}=\left[\mathbf{l}_{t}, \mathbf{d}_{t}, \mathbf{H d} \mathbf{d}_{t}, \mathbf{V d _ { t }}, \mathbf{x}_{t}, \mathbf{m}_{t}, \mathbf{a}_{t}, \mathbf{Z}^{\kappa}, \mathbf{Z}^{\lambda}\right]$ and $\boldsymbol{\beta}=\left[\beta_{0}, \ldots, \beta_{6}, \mathbf{K}^{\prime}, \lambda^{\prime}\right]^{\prime}$. We estimate alternative variants of that model and report the results in Table 1.

Table 1. Estimation results for model (1)

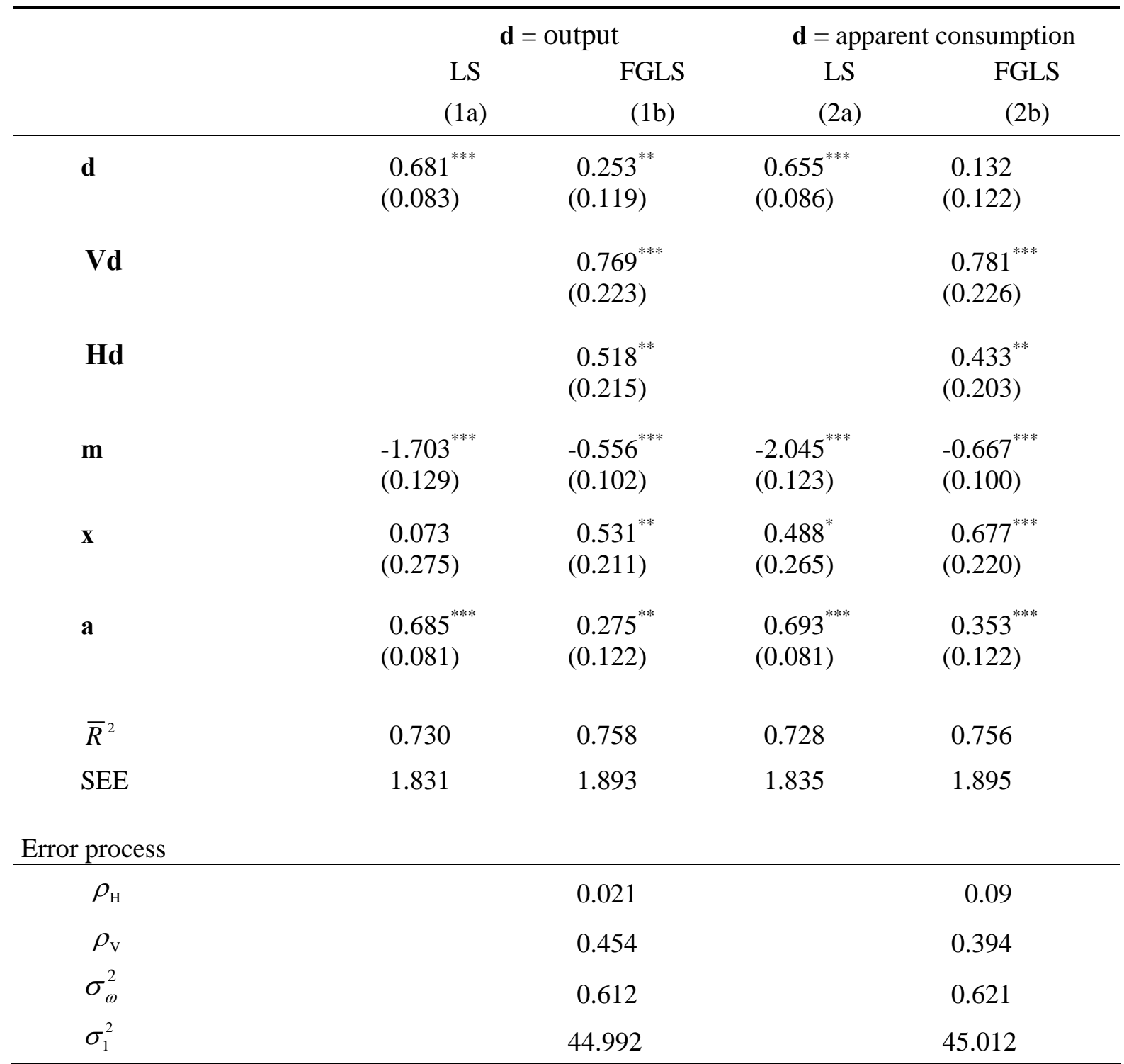

Dependent variable is log of foreign affiliate sales (y). All models include country and industry dummies and are based on a balanced panel with 2016 observations (cross-section dimension: 16 countries, 7 industries; time dimension: 1983-2000). In columns (1b) and (2b) the $\bar{R}^{2}$ is calculated from the squared correlation between actual and predicted values; the standard error of estimation (SEE) refers to feasible generalized least squares (FGLS) estimates. The GM estimates of $\rho_{\mathrm{V}}$ and $\rho_{\mathrm{H}}$ are based on least squares residuals. 
Table 1 consists of four panels of results. Those on the left-hand side are based upon gross output as a measure of local demand in a host country, while the ones on the right-hand-side use apparent consumption instead. The two panels at the top of the table report parameter estimates from the main specification given by equation (2). The two panels at the bottom summarize model characteristics as well as estimates of the parameters $\rho_{\mathrm{H}}$ and $\rho_{\mathrm{V}}$, reflecting the intensity of horizontal and vertical interdependence of FAS across host countries and industries with respect to unobservable variables.

The specifications in columns (1a) and (2a) include only four explanatory variables: Demand (gross output or apparent consumption), Exports, Imports, and Value Added/Employment. In terms of equation (2) they assume $\beta_{2}=\beta_{3}=0, \rho_{\mathrm{H}}=\rho_{\mathrm{V}}=0$, and are estimated by ordinary least squares (OLS). The specifications in columns (1b) and (2b) relax these restrictions, correspond to equation (2), and are estimated using feasible generalized least squares (FGLS).

The results may be summarized as follows. The explanatory power of the models is quite high across the board. Demand and Value Added/Employment exhibit a positive impact on bilateral FAS which is significantly different from zero. The elasticities for the two variables are quantitatively similar: a one percent increase in Demand or Value Added/Employment leads to an increase in bilateral FAS by about 0.25 percent in the specifications in columns (1b) and (2b). The corresponding elasticities are higher in the restricted specifications in columns (1a) and (2a) by almost three orders of magnitude, but these specifications are rejected against their less parsimonious counterparts. ${ }^{9}$ The absolute values of the point estimates for the parameters of Exports and Imports are very similar. In fact, the results suggest that one could use the difference between these two variables as a single regressor instead of including them independently. An increase in Exports of a particular country and industry leads to an influx of FAS by the U.S. and an increase in Imports exerts the opposite effect. After controlling for weighted Demand abroad (market potential) through $\mathbf{H d}_{t}$ and $\mathbf{V} \mathbf{d}_{t}$, and for Value Added/Employment through $\mathbf{a}_{t}$, these variables may capture time-variant political, geographical, or industry-specific impediments favorable to foreign trade. The positive impact of a country and industry's Exports and the negative one of Imports on FAS suggest that U.S. MNEs prefer locating their plants in markets with less import competition. This result also indicates that export platforms — either of the horizontal or the vertical type-seem important.

\footnotetext{
${ }^{9}$ For instance, the values of the (generalized) adjusted $R^{2}$ in columns (1b) and (2b) are higher by more than two percentage points than those in columns (1a) and (2a), respectively. Also, Wald statistics on the joint significance of the parameters of $\mathbf{H} \mathbf{d}_{t}$ and $\mathbf{V} \mathbf{d}_{t}$ are significantly different from zero.
} 
Our primary interest is whether horizontal or vertical interdependence across markets (host countries and industries) is relatively more important. Results speak a clear language: on the one hand, vertical linkages of FAS related to Demand $\left(\mathbf{V \mathbf { d } _ { t }}\right)$ enter positively and are more important than horizontal linkages $\left(\mathbf{H d}_{t}\right) \quad\left(\beta_{2}, \beta_{3}>0\right.$ and $\left.\beta_{2}>\beta_{3}\right)$; similarly, vertical linkages related to unobservable variables $\left(\mathbf{V u} \mathbf{u}_{t}\right)$ enter positively and are more important than horizontal linkages $\left(\mathbf{H u} \mathbf{u}_{t}\right)\left(\rho_{\mathrm{H}}, \rho_{\mathrm{V}}>0\right.$ and $\left.\rho_{\mathrm{V}}>\rho_{\mathrm{H}}\right)$. These findings suggest that host markets are interrelated through trade in intermediate goods, ${ }^{10}$ creating vertical interdependence in FAS across host countries and industries, and that the underlying vertical motives for MNE activity are relatively more important than horizontal ones. Given that our sample comprises a set of fairly homogeneous, highly developed host countries, this is a particularly strong finding.

\section{Sensitivity analysis}

It is the aim of this section to assess the sensitivity of the above results in various regards. In particular, we undertake the following sensitivity checks for Models 2 and 4 and summarize the findings in Table 2 (the left-hand side of the table pertains to variants of Model 2 and the right-hand side to variants of Model 4). First, we use predicted rather than actual values for horizontal and vertical linkages captured by $\mathbf{H}$ and $\mathbf{V}$ to illustrate that a possible dependence of their elements on the dependent variable (FAS of U.S. MNEs) is not a concern here. In particular, we estimate gravity-type models which include industry- and country-specific fixed effects as well as industry-pair-specific effects of bilateral distance to predict the crosssectional entries of $\mathbf{H}$ and $\mathbf{V}$, respectively (see Appendix $\mathrm{C}$ for details). In column (1a), gross output is used measure of Demand (associated with the $I J \times 1$ vector $\mathbf{d}_{t}$ for period $t$ ), whereas apparent consumption is used in column (2a). The results suggest that there is no qualitative difference as to our key conclusions about the estimates of the parameters $\beta_{2}, \beta_{3}, \rho_{\mathrm{H}}$, and $\rho_{\mathrm{v}}$ compared with Table 1 . $^{11}$

\footnotetext{
${ }^{10}$ See Eaton and Kortum (2002) for such an assumption, and Bergstrand and Egger (2008) and Jabbour (2008) for evidence on the relative importance of intermediate goods trade flows among the industrialized economies.

${ }^{11}$ Notice that the results in Models 2a and 4a take the predicted entries of $\mathbf{H}$ and $\mathbf{V}$ as data and ignore their imprecision. One could use bootstrap methods to take the latter into account but this would eventually be demanding with regard to computing time. Since the predictive power of the associated models was fairly good, we argue that the downward bias of the standard errors in Models 2a and 4a may be ignored here.
} 


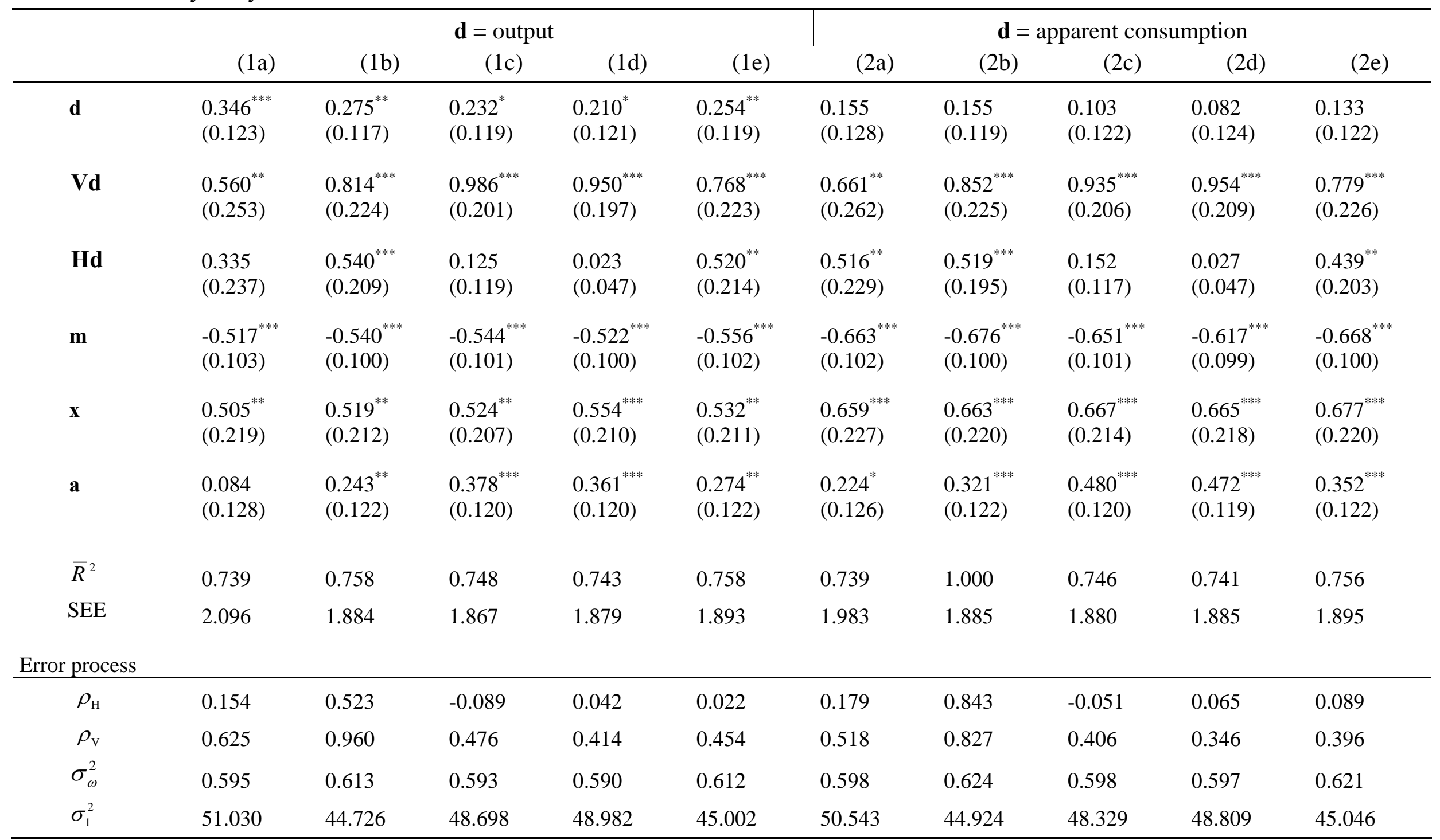

Notes: See also Table 1. All columns report FGLS estimates. The GM estimates of $\rho_{\mathrm{V}}$ and $\rho_{\mathrm{H}}$ are based on least squares residuals. The specifications in the columns are as follows: (a) predicted weight matrices $\hat{\mathbf{V}}$ and $\hat{\mathbf{H}}$ are used instead of $\mathbf{V}$ and $\mathbf{H}$. (b) $\mathbf{V}$ and $\mathbf{H}$ in error process are maximum-normalized. (c) $\mathbf{V}$ and $\mathbf{H}$ were truncated, such that the smallest 10 percent of the non-zero entries were set to zero. (d) $\mathbf{V}$ and $\mathbf{H}$ were truncated, such that the smallest 20 percent of the non-zero entries were set to zero. (e) $\mathbf{V}$ and $\mathbf{H}$ based on imports and use data rather than imports plus exports and use plus delivery data. 
Second, we change the normalization of the entries in $\mathbf{H}$ and $\mathbf{V}$ by using the maximum row sum (i.e., a scalar) rather than each row's sum (i.e., a row vector) to normalize the entries of the underlying matrices. While the row-normalization employed in the specifications in Table 1 implies that only relative horizontal or vertical interdependence matters between host countries and industries, maximum row sum normalization postulates that the absolute level of horizontal or vertical goods trade shares matters rather than the relative share. Again, the results are suggestive: while the estimates of $\rho_{\mathrm{H}}$ and $\rho_{\mathrm{V}}$ under row-normalization were in the permissible parameter space, the ones under maximum row-normalization in columns (1b) and (2b) of Table 2 are not. This result indicates that maximum row-sum normalization of the interdependence matrices $\mathbf{H}$ and $\mathbf{V}$ is less appropriate than row-normalization for the data and model at hand.

Third, we consider two alternative versions for a cut-off value of the entries of the unnormalized interdependence matrices underlying $\mathbf{H}$ and $\mathbf{V}$. So far, we assumed that (unnormalized) interdependence declines linearly with less horizontal and vertical trade, respectively. In the sensitivity checks summarized in columns (1c) and (2c), we assume that unnormalized interdependence is equal to zero for the smallest 10 percent of positive horizontal and vertical trade flows as a share of gross output each. In columns (1d) and (2d), we set the smallest 20 percent of the horizontal and vertical trade flows to zero instead. This establishes a non-monotonic decay function of interdependence, suggesting that some minimal level of trade is necessary to create interdependent FAS across countries and industries. The corresponding estimates in Table 2 indicate that the results obtained so far are qualitatively insensitive to such modifications of the interdependence decay function.

Finally, we change the content of the matrices $\mathbf{H}$ and $\mathbf{V}$ by combining only import trade data with use data from input-output tables rather than export plus import trade data with make and use input-output data. There are two reasons for such a sensitivity check: on the one hand, it is accepted that imports are measured more accurately than export; on the other hand, it seems plausible that at least horizontal interdependence is stronger related to-import competition rather than export competition. For instance, a country which imports a lot from another economy where U.S. FAS are large is likely to be served through export platforms there rather than local FAS by U.S. MNEs. Such interdependence might be less strongly related to export relationships. The corresponding estimates are reported in columns (1e) and (2e) of Table 2. Comparing the results to their counterparts in columns (1b) and (2b) of Table 1 there is no qualitative difference to the original findings: interdependence matters more strongly for vertically linked markets than for horizontally linked ones, irrespective of whether we 
consider demand linkages captured by $\mathbf{H d}_{t}$ and $\mathbf{V \mathbf { d } _ { t }}$ or linkages with respect to unobservable factors, i.e., $\rho_{\mathrm{H}} \mathbf{H u} \mathbf{u}_{t}$ and $\rho_{\mathrm{V}} \mathbf{V} \mathbf{u}_{t}$, respectively.

Overall, we conclude that the results in Table 1 are qualitatively robust and go on to quantify the role of horizontal and vertical interdependence in the sequel, using the preferred specification in column (1b) of Table $1 .^{12}$

\section{Quantification of the role of vertical versus horizontal interdependence}

In the subsequent discussion, it is useful to distinguish between (horizontal and vertical) interdependence related to market size (demand)—created by $\beta_{2} \mathbf{H} \mathbf{d}_{t}+\beta_{3} \mathbf{V d}$ in equation (3) — on the one hand, and interdependence related to unobservable variables — created by $\mathbf{u}_{t}=\left(\mathbf{I}-\rho_{\mathrm{H}} \mathbf{H}+\rho_{\mathrm{V}} \mathbf{V}\right)^{-1}\left(\boldsymbol{\mu}+\boldsymbol{\omega}_{t}\right)$ through equation (1)—on the other hand. For a quantification of the impact of linkage effects, note that a shock in $\mathbf{d}_{t}$ triggers immediate effects only, while a shock in the unobservable variables $\left(\boldsymbol{\mu}+\boldsymbol{\omega}_{t}\right)$ leads to direct and indirect effects through the linkage ‘multiplier' $\left(\mathbf{I}-\rho_{\mathrm{H}} \mathbf{H}-\rho_{\mathrm{V}} \mathbf{V}\right)^{-1}$.

A unitary shock in Demand across all countries and industries $\left(\mathbf{t}_{t}\right)$ creates a horizontal linkage effect of $\beta_{2}$ and a vertical one of $\beta_{3}$. Since $\mathbf{d}_{t}$ is expressed in logarithmic form, $\beta_{2}$ and $\beta_{3}$ reflect demand linkage elasticities. This is due to the fact that $\mathbf{H}$ and $\mathbf{V}$ are rownormalized in Model 2 and a unitary change in $\mathbf{d}_{t}$ always translates into a change in FAS of $\left(\beta_{2}+\beta_{3}\right) \mathbf{t}_{t}$. Hence, we may conclude that the vertical demand linkage elasticity is almost twice as large as the horizontal one.

Linkage effects through the unobservable variables generate more complex, non-linear effects. Again, the normalization of both $\mathbf{H}$ and $\mathbf{V}$ helps in the formulation, since a unitary shock in $\left(\boldsymbol{\mu}+\boldsymbol{\omega}_{t}\right)$ translates into an effect on FAS of $\left(\mathbf{I}-\rho_{\mathrm{H}} \mathbf{H}-\rho_{\mathrm{V}} \mathbf{V}\right)^{-1} \mathbf{l}_{t}$. The average effect associated with such a shock on a host-country-industry-dyad's FAS of the U.S. is then $(1 / I J) \mathbf{l}_{t}^{\prime}\left(\mathbf{I}-\rho_{\mathrm{H}} \mathbf{H}-\rho_{\mathrm{V}} \mathbf{V}\right)^{-1} \mathbf{l}_{t}$, which amounts to $1 /\left(1-\rho_{\mathrm{H}}-\rho_{\mathrm{V}}\right)$ with row-normalized matrices $\mathbf{H}$ and $\mathbf{V}$. Hence, our estimates suggest that a unitary shock in $\left(\boldsymbol{\mu}+\boldsymbol{\omega}_{t}\right)$ leads to a

\footnotetext{
${ }^{12}$ Comparing the coefficients with those in column (2b) of Table 1, it is evident that the quantitative implications of these two specifications considered in the next section are very similar.
} 
change in average bilateral FAS of 1.94 percent, of which the lion's share is made up by vertical linkages according to the estimates of $\rho_{\mathrm{H}}$ and $\rho_{\mathrm{V}}$ in Table 1. Unlike with demand linkages, however, a linear decomposition of the 'impact multiplier' $\left(\mathbf{I}-\rho_{\mathrm{H}} \mathbf{H}-\rho_{\mathrm{V}} \mathbf{V}\right)^{-1}$ is infeasible due to the non-linear and intertwined propagation of incipient horizontal $\left(\rho_{\mathrm{H}} \mathbf{H}\right)$ and vertical interdependence effects $\left(\rho_{\mathrm{V}} \mathbf{V}\right)$.

\section{Concluding remarks}

This paper analyzes the role of horizontal versus vertical linkage effects in multinational activity across host countries and industries. We combine bilateral trade and input-output data for 16 countries and 7 industries to construct measures of horizontal and vertical linkages across host countries and industries in foreign affiliate sales (FAS) of U.S. MNEs. We distinguish between interdependence related to market size (demand) and other, not further specified interdependence related to unobservable factors. Using a panel data set covering the years 1983-2000, we find that vertical demand linkage effects are more important than horizontal ones by one order of magnitude; vertical linkage effects in unobservable variables are more important than horizontal ones by several orders of magnitude.

Our findings are based on a sample of fairly homogeneous, highly developed host countries. They indicate that vertical motives of multinational activity even among such countries may be much more important than previously thought. In particular, the results suggest that small factor cost and endowment differences among developed countries alone are insufficient to interpret previous evidence about multinational activity as pointing to a dominance of horizontal relationships across host countries and affiliates. 


\section{References}

Amemiya, T. (1971), The estimation of the variances in a variance-component model, International Economic Review 12, 1-13.

Anderson, J.E. and E. van Wincoop (2003), Gravity with gravitas: A solution to the border puzzle, American Economic Review 93, 170-92.

Anselin, L. (1988), Spatial Econometrics: Methods and Models, Dordrecht: Kluwer, 1988.

Badinger, H. and P. Egger (2008), GM estimation of higher order spatial autoregressive processes in panel data error component models, CESifo Working paper, No.2301, May 2008.

Baltagi, B.H., P. Egger, and M. Pfaffermayr (2007), Estimating models of complex FDI: Are there third-country effects?, Journal of Econometrics 140, 260-81.

Bergstrand, J.H. and P. Egger (2008), Outsourcing: International trade, foreign direct investment, and outsourcing, unpublished manuscript, University of Notre Dame.

Blonigen, B.A., R.B., Davies, G. Waddell, and H. Naughton (2007), FDI in space: Spatial autoregressive relationships in foreign direct investment, European Economic Review 51, 1303-25.

Coughlin, C.C. and E. Segev (2000), Foreign direct investment in China: A spatial econometric study, The World Economy 23, 1-23.

Eaton, J. and S. Kortum (2002), Technology, geography, and trade, Econometrica 70, 174179.

Egger, H., P. Egger, and M. Ryan (2007), Exchange rate effects on multinational activity: Theory and evidence, unpublished manuscript, University of Munich.

Ekholm, K, R. Forslid, and J.R. Markusen (2007), Export-platform foreign direct investment, Journal of the European Economic Association 5, 776-95.

Feenstra, R.C. and G.H. Hanson (1999), The impact of outsourcing and high technology capital on wages: Estimates for the United States, 1979-1990, Quarterly Journal of Economics 114, 907-940.

Grossman, G.M., E. Helpman, and A. Szeidl (2007), Optimal integration strategies for the multinational firm, Journal of International Economics 70, 216-38.

Helpman, E. (1984), A simple theory of trade with multinational corporations, Journal of Political Economy 92, 451-71. 
Helpman, E. (1985), Multinational corporations and trade structure, Review of Economic Studies 52, 443-57.

Helpman, E. and P.R. Krugman (1985), Market Structure and Foreign Trade, Cambridge, MA: The MIT Press.

Jabbour, L. (2008), Slicing the value added chain internationally: Empirical evidence on the offshoring strategy by French firms, unpublished manuscript, University of Nottingham.

Kapoor, M., H.H. Kelejian, and I.R. Prucha (2007), Panel data models with spatially correlated error components, Journal of Econometrics 140, 97-130.

Kelejian, H.H. and I.R. Prucha (1999), A generalized moments estimator for the autoregresssive parameter in a spatial model, International Economic Review 40, 50933.

Lee, L.-F. (2004), Asymptotic distribution of maximum likelihood estimators for spatial autoregressive models, Econometrica 72, 1899-1925.

Markusen, J.R. (1984), Multinational, multi-plant economies, and the gains from trade, Journal of International Economics 16, 205-26.

Markusen, J.R. (2002), Multinational Firms and the Theory of International Trade, Cambridge, MA: The MIT Press.

Markusen, J.R. and A.J. Venables (2000), The theory of endowment, intra-industry and multinational trade, Journal of International Economics 52, 209-34.

Yeaple, S.R. (2003), The complex integration strategies of multinationals and cross country dependencies in the structure of FDI, Journal of International Economics 60, 293-314. 


\section{Appendix A. Estimation of model (1): Econometric issues}

\section{A1. GM estimation of second order spatial regressive error process with panel data}

\section{A1.1 General remarks and notation}

To estimate the spatial regressive error process in model (1), we utilize the GM estimation approach introduced by Kelejian and Prucha (1999) in the context of a cross-section model. Kapoor, Kelejian, and Prucha (2007) have extended this estimator to the case of a panel data error components model with a first order spatial regressive process. In order to estimate model (1), which specifies a second order spatial regressive process, we rely on recent work by Badinger and Egger (2008), who have extended the estimator by Kapoor, Kelejian, and Prucha (2007) to the general case of an $R$-th order spatial regressive process. In the following we outline the application of this estimator to model (1). ${ }^{13}$

Stacking observations by time period, model (1) reads as follows:

$$
\mathbf{y}=\mathbf{X} \boldsymbol{\beta}+\mathbf{u} .
$$

For simplicity of notation, define the index $n=1, \ldots, N=I J$. Then $\mathbf{y}=\left[\mathbf{y}_{1}^{\prime}, \ldots, \mathbf{y}_{T}^{\prime}\right]^{\prime}$ is the $N T \times$ 1 vector of observations on the dependent variable in period $t$ and the $N T \times K$ regressor matrix is given by $\mathbf{X}=\left[\mathbf{X}_{1}^{\prime}, \ldots, \mathbf{X}_{T}^{\prime}\right]^{\prime}$.

The spatial regressive error process reads

$$
\mathbf{u}=\rho_{\mathrm{H}}\left(\mathbf{I}_{T} \otimes \mathbf{H}\right) \mathbf{u}+\rho_{\mathrm{V}}\left(\mathbf{I}_{T} \otimes \mathbf{V}\right) \mathbf{u}+\boldsymbol{\varepsilon},
$$

where $\mathbf{u}=\left[\mathbf{u}_{1}^{\prime}, \ldots, \mathbf{u}_{T}^{\prime}\right]^{\prime}$ and $\mathbf{I}_{T}$ is an $T \times T$ identity matrix. The $N T \times 1$ vector $\boldsymbol{\varepsilon}$ of error terms consists of two components:

$$
\boldsymbol{\varepsilon}=\left(\mathbf{e}_{T} \otimes \mathbf{I}_{N}\right) \boldsymbol{\mu}+\boldsymbol{\omega},
$$

where $\mathbf{e}_{T}$ is a unit vector of dimension $T \times 1, \boldsymbol{\mu}=\left[\mu_{1}, \mu_{2}, \ldots, \mu_{N}\right]^{\prime}$ is the $N \times 1$ vector of unit specific error components, which are assumed to be independently and identically distributed

\footnotetext{
${ }^{13}$ For details on this estimator and the proof of consistency the reader is referred to Badinger and Egger (2008).
} 
with mean zero and variance $\sigma_{\mu}^{2}$. Finally, $\omega$ is the $N T \times 1$ vector of innovations $\omega_{n, t}$, which are assumed to be independent of $\mu$ and independently and identically distributed with zero mean and variance $\sigma_{\omega}^{2}$.

As a consequence, the variance-covariance matrix of the stacked error term $\varepsilon$ is given by

$$
\mathbf{\Omega}_{\varepsilon}=E\left[\boldsymbol{\varepsilon \varepsilon}^{\prime}\right]=\sigma_{\mu}^{2}\left(\mathbf{J}_{T} \otimes \mathbf{I}_{N}\right)+\sigma_{\omega}^{2} \mathbf{I}_{N T}
$$

where $\mathbf{J}_{T}=\mathbf{e}_{T} \mathbf{e}_{T}^{\prime}$ is a $T \times T$ matrix with unit elements and $\mathbf{I}_{N T}$ is an identity matrix of dimension $N T \times N T$. Equation (4) can also be written as

$$
\mathbf{\Omega}_{\varepsilon, N}=\sigma_{\omega}^{2} \mathbf{Q}_{0}+\sigma_{1}^{2} \mathbf{Q}_{1},
$$

where $\sigma_{1}^{2}=\sigma_{\omega}^{2}+T \sigma_{\mu}^{2}$. The two matrices $\mathbf{Q}_{0}$ and $\mathbf{Q}_{1}$ which are central to the estimation of error component models and the moment conditions of the GM estimator, are defined as

$$
\begin{aligned}
& \mathbf{Q}_{0}=\left(\mathbf{I}_{T}-\frac{\mathbf{J}_{T}}{T}\right) \otimes \mathbf{I}_{N}, \text { and } \\
& \mathbf{Q}_{1}=\frac{\mathbf{J}_{T}}{T} \otimes \mathbf{I}_{N} \text {, where } \mathbf{J}_{T}=\mathbf{e}_{T} \mathbf{e}_{T}^{\prime} .
\end{aligned}
$$

Both $\mathbf{Q}_{0}$ and $\mathbf{Q}_{1}$ are of order $N T \times N T$, symmetric, idempotent, orthogonal to each other and sum up to $\mathbf{I}_{N T}$.

For later reference, note that

$$
\boldsymbol{\varepsilon}=\mathbf{u}-\rho_{\mathrm{H}}\left(\mathbf{I}_{T} \otimes \mathbf{H}\right) \mathbf{u}-\rho_{\mathrm{V}}\left(\mathbf{I}_{T} \otimes \mathbf{V}\right) \mathbf{u}
$$

and

$$
\mathbf{u}=\left[\mathbf{I}_{T} \otimes\left(\mathbf{I}_{N}-\rho_{\mathrm{H}} \mathbf{H}-\rho_{\mathrm{V}} \mathbf{V}\right)^{-1}\right] \boldsymbol{\varepsilon} .
$$

It follows that the variance-covariance matrix of $\mathbf{u}$ is given by 


$$
\boldsymbol{\Omega}_{u}=E\left[\mathbf{u} \mathbf{u}^{\prime}\right]=\left[\mathbf{I}_{T} \otimes\left(\mathbf{I}_{N}-\rho_{\mathrm{H}} \mathbf{H}-\rho_{\mathrm{V}} \mathbf{V}\right)^{-1}\right] \boldsymbol{\Omega}_{\varepsilon}\left[\mathbf{I}_{T} \otimes\left(\mathbf{I}_{N}-\rho_{\mathrm{H}} \mathbf{H}-\rho_{\mathrm{V}} \mathbf{V}\right)^{-1}\right]
$$

\section{A1.2 Moment conditions}

Kapoor, Kelejian, and Prucha (2007) use 6 moment conditions to estimate the spatial regressive parameter of a first order spatial regressive parameter. These moment conditions are based on quadratic forms of the vector $\boldsymbol{\varepsilon}$ in the spatial weighting matrix (and $\mathbf{Q}_{0}$ and $\mathbf{Q}_{1}$ ). In our case of the second order process, the GM estimates of $\rho_{\mathrm{H}}$ and $\rho_{\mathrm{V}}$ can be obtained by recognizing that the moment conditions given by Kapoor, Kelejian, and Prucha (2007), involving the spatial weighting matrix, must hold for both matrices $\mathbf{H}$ and $\mathbf{V}$.

Define

$$
\overline{\boldsymbol{\varepsilon}}_{\mathrm{H}}=\left(\mathbf{I}_{T} \otimes \mathbf{H}\right) \boldsymbol{\varepsilon}=\left(\mathbf{I}_{T} \otimes \mathbf{H}\right)\left(\mathbf{u}-\rho_{\mathrm{H}}\left(\mathbf{I}_{T} \otimes \mathbf{H}\right) \mathbf{u}-\rho_{\mathrm{V}}\left(\mathbf{I}_{T} \otimes \mathbf{V}\right) \mathbf{u}\right) .
$$

Associated with matrix $\mathbf{H}$ we have the following moment conditions:

$$
\begin{aligned}
& \mathrm{M}_{1, \mathrm{H}} E\left[\frac{1}{N(T-1)} \overline{\boldsymbol{\varepsilon}}_{\mathrm{H}}^{\prime} \mathbf{Q}_{0} \overline{\boldsymbol{\varepsilon}}_{\mathrm{H}}\right]=\sigma_{\omega}^{2} \frac{1}{N} \operatorname{tr}\left(\mathbf{H}^{\prime} \mathbf{H}\right), \\
& \mathrm{M}_{2, \mathrm{H}} E\left[\frac{1}{N(T-1)} \overline{\boldsymbol{\varepsilon}}_{\mathrm{H}}^{\prime} \mathbf{Q}_{0} \boldsymbol{\varepsilon}\right]=0, \\
& \mathrm{M}_{3, \mathrm{H}} E\left[\frac{1}{N} \overline{\boldsymbol{\varepsilon}}_{\mathrm{H}}^{\prime} \mathbf{Q}_{1} \overline{\boldsymbol{\varepsilon}}_{\mathrm{H}}\right]=\sigma_{1}^{2} \frac{1}{N} \operatorname{tr}\left(\mathbf{H}^{\prime} \mathbf{H}\right), \\
& \mathrm{M}_{4, \mathrm{H}} E\left[\frac{1}{N} \overline{\boldsymbol{\varepsilon}}_{\mathrm{H}}^{\prime} \mathbf{Q}_{1} \boldsymbol{\varepsilon}\right]=0 .{ }^{14}
\end{aligned}
$$

Next define

$$
\overline{\boldsymbol{\varepsilon}}_{\mathrm{V}}=\left(\mathbf{I}_{T} \otimes \mathbf{V}\right) \boldsymbol{\varepsilon}=\left(\mathbf{I}_{T} \otimes \mathbf{V}\right)\left(\mathbf{u}-\rho_{\mathrm{V}}\left(\mathbf{I}_{T} \otimes \mathbf{H}\right) \mathbf{u}-\rho_{\mathrm{H}}\left(\mathbf{I}_{T} \otimes \mathbf{V}\right) \mathbf{u}\right) .
$$

Associated with matrix $\mathbf{V}$, we have the following moment conditions:

$$
\begin{aligned}
& \mathrm{M}_{1, \mathrm{~V}} E\left[\frac{1}{N(T-1)} \overline{\boldsymbol{\varepsilon}}_{\mathrm{V}}^{\prime} Q_{0} \overline{\boldsymbol{\varepsilon}}_{\mathrm{V}}\right]=\sigma_{\omega}^{2} \frac{1}{N} \operatorname{tr}\left(\mathbf{V}^{\prime} \mathbf{V}\right), \\
& \mathrm{M}_{2, \mathrm{~V}} E\left[\frac{1}{N(T-1)} \overline{\boldsymbol{\varepsilon}}_{\mathrm{V}}^{\prime} Q_{0} \boldsymbol{\varepsilon}\right]=0,
\end{aligned}
$$

\footnotetext{
${ }^{14}$ The expression $\operatorname{tr}$ denotes the trace operator.
} 


$$
\begin{aligned}
& \mathrm{M}_{3, \mathrm{~V}} E\left[\frac{1}{N} \overline{\boldsymbol{\varepsilon}}_{\mathrm{V}}^{\prime} Q_{1} \overline{\boldsymbol{\varepsilon}}_{\mathrm{V}}\right]=\sigma_{1}^{2} \frac{1}{N} \operatorname{tr}\left(\mathbf{V}^{\prime} \mathbf{V}\right), \\
& \mathrm{M}_{4, \mathrm{~V}} E\left[\frac{1}{N} \overline{\boldsymbol{\varepsilon}}_{\mathrm{V}}^{\prime} Q_{1} \boldsymbol{\varepsilon}\right]=0 .
\end{aligned}
$$

Finally, there are two moment conditions that do not depend on the weighting matrices:

$$
\begin{aligned}
& \mathrm{M}_{\mathrm{a}} \quad E\left[\frac{1}{N(T-1)} \boldsymbol{\varepsilon}^{\prime} \mathbf{Q}_{0} \boldsymbol{\varepsilon}\right]=\sigma_{\omega}^{2}, \\
& \mathrm{M}_{\mathrm{b}} \quad E\left[\frac{1}{N} \boldsymbol{\varepsilon}^{\prime} \mathbf{Q}_{1} \boldsymbol{\varepsilon}\right]=\sigma_{1}^{2}, \text { where } \sigma_{1}^{2}=\sigma_{\omega}^{2}+T \sigma_{\mu}^{2} .
\end{aligned}
$$

\section{A1.3 Definition of GM estimator}

Substituting (A.11) into the 10 moment conditions given by (A.12), (A.14), (A.15) and (A.16) yields a 10 equation-system, given by

$$
\gamma-\Gamma \boldsymbol{\alpha}=\mathbf{0}
$$

The parameter vector $\boldsymbol{\alpha}=\left(\rho_{\mathrm{H}}, \rho_{\mathrm{V}}, \rho_{\mathrm{H}}^{2}, \rho_{\mathrm{V}}^{2}, \rho_{\mathrm{H}} \rho_{\mathrm{V}}, \sigma_{\omega}^{2}, \sigma_{1}^{2}\right)^{\prime}$ is of dimension $7 \times 1 ; \gamma$ is a $10 \times 1$ vector with elements $\left[\gamma_{r}\right]$, with $r=1, \ldots, 10$, and $\boldsymbol{\Gamma}$ is a $10 \times 7$ matrix with elements $\left[\gamma_{r, c}\right]$ with $r=1, \ldots, 10, c=1, \ldots, 7$.

The GM estimates of $\rho_{\mathrm{V}}, \rho_{\mathrm{H}}, \sigma_{\omega}^{2}$, and $\sigma_{1}^{2}$ are then obtained as

$$
\left(\tilde{\rho}_{\mathrm{H}}, \tilde{\rho}_{\mathrm{V}}, \tilde{\sigma}_{\omega}^{2}, \tilde{\sigma}_{1}^{2}\right)=\underset{\rho_{\mathrm{H}}, \rho_{\mathrm{V}}, \sigma_{\omega}^{2}, \sigma_{1}^{2}}{\arg \min }\left[(\tilde{\boldsymbol{\gamma}}-\tilde{\boldsymbol{\Gamma}} \boldsymbol{\alpha})^{\prime} \boldsymbol{\Lambda}(\tilde{\boldsymbol{\gamma}}-\tilde{\boldsymbol{\Gamma}} \boldsymbol{\alpha})\right]
$$

where the vector $\tilde{\gamma}$ and the matrix $\tilde{\boldsymbol{\Gamma}}$ are the sample counterparts of $\boldsymbol{\gamma}$ and $\boldsymbol{\Gamma}$, obtained by suppressing the expectations operator in the expressions below and replacing $\mathbf{u}$ by consistent estimates $\tilde{\mathbf{u}}$. The matrix $\Lambda$ is an arbitrary weighting matrix, which will be discussed more in detail below. Define

$$
\begin{aligned}
& \overline{\mathbf{u}}_{\mathrm{H}}=\left(\mathbf{I}_{T} \otimes \mathbf{H}\right) \mathbf{u}, \overline{\mathbf{u}}_{\mathrm{V}}=\left(\mathbf{I}_{T} \otimes \mathbf{V}\right) \mathbf{u}, \overline{\overline{\mathbf{u}}}_{\mathrm{H}}=\left(\mathbf{I}_{T} \otimes \mathbf{H}\right)\left(\mathbf{I}_{T} \otimes \mathbf{H}\right) \mathbf{u}=\left(\mathbf{I}_{T} \otimes \mathbf{H}^{2}\right) \mathbf{u} \\
& \overline{\overline{\mathbf{u}}}_{\mathrm{V}}=\left(\mathbf{I}_{T} \otimes \mathbf{V}\right)\left(\mathbf{I}_{T} \otimes \mathbf{V}\right) \mathbf{u}=\left(\mathbf{I}_{T} \otimes \mathbf{V}^{2}\right) \mathbf{u}, \overline{\overline{\mathbf{u}}}_{\mathrm{HV}}=\left(\mathbf{I}_{T} \otimes \mathbf{H}\right)\left(\mathbf{I}_{T} \otimes \mathbf{V}\right) \mathbf{u}=\left(\mathbf{I}_{T} \otimes \mathbf{H V}\right) \mathbf{u} \\
& \overline{\overline{\mathbf{u}}}_{\mathrm{VH}}=\left(\mathbf{I}_{T} \otimes \mathbf{V}\right)\left(\mathbf{I}_{T} \otimes \mathbf{H}\right) \mathbf{u}=\left(\mathbf{I}_{T} \otimes \mathbf{V H}\right) \mathbf{u}
\end{aligned}
$$


In Table A1, we define the elements of $\boldsymbol{\gamma}$ and $\boldsymbol{\Gamma}$, grouped the underlying moment condition and the corresponding rows in equation system (A.17).

Table A. Definition of the elements of $\boldsymbol{\gamma}$ and $\boldsymbol{\Gamma}$ in equation system (A.17)

\begin{tabular}{|c|c|}
\hline Moment condition $\mathrm{M}_{1, \mathrm{H}}$ (row 1$)$ & Moment condition $\mathrm{M}_{2, \mathrm{H}}$ (row 2) \\
\hline$\gamma_{1}=\frac{1}{N(T-1)} E\left[\overline{\mathbf{u}}_{\mathrm{H}}^{\prime} \mathbf{Q}_{0} \overline{\mathbf{u}}_{\mathrm{H}}\right]$ & $\gamma_{2}=\frac{1}{N(T-1)} E\left[\overline{\mathbf{u}}_{\mathrm{H}}^{\prime} \mathbf{Q}_{0} \mathbf{u}\right]$ \\
\hline$\gamma_{1,1}=\frac{2}{N(T-1)} E\left[\overline{\mathbf{u}}_{\mathrm{H}}^{\prime} \mathbf{Q}_{0} \overline{\overline{\mathbf{u}}}_{\mathrm{H}}\right]$ & $\gamma_{2,1}=\frac{1}{N(T-1)} E\left[\overline{\overline{\mathbf{u}}}_{\mathrm{H}}^{\prime} \mathbf{Q}_{0} \mathbf{u}+\overline{\mathbf{u}}_{\mathrm{H}}^{\prime} \mathbf{Q}_{0} \overline{\mathbf{u}}_{\mathrm{H}}\right]$ \\
\hline$\gamma_{1,2}=\frac{2}{N(T-1)} E\left[\overline{\mathbf{u}}_{\mathrm{H}}^{\prime} \mathbf{Q}_{0} \overline{\overline{\mathbf{u}}}_{\mathrm{HV}}\right]$ & $\gamma_{2,2}=\frac{1}{N(T-1)} E\left[\overline{\overline{\mathbf{u}}}_{\mathrm{HV}}^{\prime} \mathbf{Q}_{0} \mathbf{u}+\overline{\mathbf{u}}_{\mathrm{H}}^{\prime} \mathbf{Q}_{0} \overline{\mathbf{u}}_{\mathrm{V}}\right]$ \\
\hline$\gamma_{1,3}=-\frac{1}{N(T-1)} E\left[\overline{\overline{\mathbf{u}}}_{\mathrm{H}}^{\prime} \mathbf{Q}_{0} \overline{\overline{\mathbf{u}}}_{\mathrm{H}}\right]$ & $\gamma_{2,3}=-\frac{1}{N(T-1)} E\left[\overline{\overline{\mathbf{u}}}_{\mathrm{HH}}^{\prime} \mathbf{Q}_{0} \overline{\mathbf{u}}_{\mathrm{H}}\right]$ \\
\hline$\gamma_{1,4}=-\frac{1}{N(T-1)} E\left[\overline{\overline{\mathbf{u}}}_{\mathrm{HV}}^{\prime} \mathbf{Q}_{0} \overline{\overline{\mathbf{u}}}_{\mathrm{HV}}\right]$ & $\gamma_{2,4}=-\frac{1}{N(T-1)} E\left[\overline{\overline{\mathbf{u}}}_{\mathrm{HV}}^{\prime} \mathbf{Q}_{0} \overline{\mathbf{u}}_{\mathrm{V}}\right]$ \\
\hline$\gamma_{1,5}=-\frac{2}{N(T-1)} E\left[\overline{\overline{\mathbf{u}}}_{\mathrm{H}}^{\prime} \mathbf{Q}_{0} \overline{\overline{\mathbf{u}}}_{\mathrm{HV}}\right]$ & $\gamma_{2,5}=-\frac{1}{N(T-1)} E\left[\overline{\overline{\mathbf{u}}}_{\mathrm{HV}}^{\prime} \mathbf{Q}_{0} \overline{\mathbf{u}}_{\mathrm{H}}+\overline{\overline{\mathbf{u}}}_{\mathrm{H}}^{\prime} \mathbf{Q}_{0} \overline{\mathbf{u}}_{\mathrm{V}}\right]$ \\
\hline$\gamma_{1,6}=\frac{1}{N} \operatorname{tr}\left(\mathbf{H}^{\prime} \mathbf{H}\right)$ & $\gamma_{2,6}=0$ \\
\hline$\gamma_{1,7}=0$ & $\gamma_{2,7}=0$ \\
\hline
\end{tabular}

Moment condition $\mathrm{M}_{1, \mathrm{~V}}$ (rows 5)

Moment condition $\mathrm{M}_{2, \mathrm{~V}}$ (rows 6)

\begin{tabular}{|c|c|}
\hline$\gamma_{5}=\frac{1}{N(T-1)} E\left[\overline{\mathbf{u}}_{\mathrm{V}}^{\prime} \mathbf{Q}_{0} \overline{\mathbf{u}}_{\mathrm{V}}\right]$ & $\gamma_{6}=\frac{1}{N(T-1)} E\left[\overline{\mathbf{u}}_{\mathrm{V}}^{\prime} \mathbf{Q}_{0} \mathbf{u}\right]$ \\
\hline$\gamma_{5,1}=\frac{2}{N(T-1)} E\left[\overline{\mathbf{u}}_{\mathrm{V}}^{\prime} \mathbf{Q}_{0} \overline{\overline{\mathbf{u}}}_{\mathrm{VH}}\right]$ & $\gamma_{6,1}=\frac{1}{N(T-1)} E\left[\overline{\overline{\mathbf{u}}}_{\mathrm{VH}}^{\prime} \mathbf{Q}_{0} \mathbf{u}+\overline{\mathbf{u}}_{\mathrm{V}}^{\prime} \mathbf{Q}_{0} \overline{\mathbf{u}}_{\mathrm{H}}\right]$ \\
\hline$\gamma_{5,2}=\frac{2}{N(T-1)} E\left[\overline{\mathbf{u}}_{\mathrm{V}}^{\prime} \mathbf{Q}_{0} \overline{\overline{\mathbf{u}}}_{\mathrm{V}}\right]$ & $\gamma_{6,2}=\frac{1}{N(T-1)} E\left[\overline{\overline{\mathbf{u}}}_{\mathrm{V}}^{\prime} \mathbf{Q}_{0} \mathbf{u}+\overline{\mathbf{u}}_{\mathrm{V}}^{\prime} \mathbf{Q}_{0} \overline{\mathbf{u}}_{\mathrm{V}}\right]$ \\
\hline$\gamma_{5,3}=-\frac{1}{N(T-1)} E\left[\overline{\overline{\mathbf{u}}}_{\mathrm{VH}}^{\prime} \mathbf{Q}_{0} \overline{\overline{\mathbf{u}}}_{\mathrm{VH}}\right]$ & $\gamma_{6,3}=-\frac{1}{N(T-1)} E\left[\overline{\overline{\mathbf{u}}}_{\mathrm{VH}}^{\prime} \mathbf{Q}_{0} \overline{\mathbf{u}}_{\mathrm{H}}\right]$ \\
\hline$\gamma_{5,4}=-\frac{1}{N(T-1)} E\left[\overline{\overline{\mathbf{u}}}_{\mathrm{V}}^{\prime} \mathbf{Q}_{0} \overline{\overline{\mathbf{u}}}_{\mathrm{V}}\right]$ & $\gamma_{6,4}=-\frac{1}{N(T-1)} E\left[\overline{\overline{\mathbf{u}}}_{\mathrm{V}}^{\prime} \mathbf{Q}_{0} \overline{\mathbf{u}}_{\mathrm{V}}\right]$ \\
\hline$\gamma_{5,5}=-\frac{2}{N(T-1)} E\left[\overline{\overline{\mathbf{u}}}_{\mathrm{VH}}^{\prime} \mathbf{Q}_{0} \overline{\overline{\mathbf{u}}}_{\mathrm{V}}\right]$ & $\gamma_{6,5}=-\frac{1}{N(T-1)} E\left[\overline{\overline{\mathbf{u}}}_{\mathrm{V}}^{\prime} \mathbf{Q}_{0} \overline{\mathbf{u}}_{\mathrm{H}}+\overline{\overline{\mathbf{u}}}_{\mathrm{VH}}^{\prime} \mathbf{Q}_{0} \overline{\mathbf{u}}_{\mathrm{V}}\right]$ \\
\hline$\gamma_{5,6}=\frac{1}{N} \operatorname{tr}\left(\mathbf{V}^{\prime} \mathbf{V}\right)$ & $\gamma_{6,6}=0$ \\
\hline$\gamma_{5,7}=0$ & $\gamma_{6,7}=0$ \\
\hline
\end{tabular}


Table A (continued). Definition of the elements of $\gamma$ and $\boldsymbol{\Gamma}$ in equation system (A.17)

\begin{tabular}{|c|c|}
\hline Moment condition $\mathrm{M}_{3, \mathrm{H}}$ (row 3) & Moment condition $\mathrm{M}_{4, \mathrm{H}}$ (row 4) \\
\hline$\gamma_{3}=\frac{1}{N} E\left[\overline{\mathbf{u}}_{\mathrm{H}}^{\prime} \mathbf{Q}_{1} \overline{\mathbf{u}}_{\mathrm{H}}\right]$ & $\gamma_{4}=\frac{1}{N} E\left[\overline{\mathbf{u}}_{\mathrm{H}}^{\prime} \mathbf{Q}_{1, N} \mathbf{u}\right]$ \\
\hline$\gamma_{3,1}=\frac{2}{N} E\left[\overline{\mathbf{u}}_{\mathrm{H}}^{\prime} \mathbf{Q}_{1} \overline{\overline{\mathbf{u}}}_{\mathrm{H}}\right]$ & $\gamma_{4,1}=\frac{1}{N} E\left[\overline{\overline{\mathbf{u}}}_{\mathrm{H}}^{\prime} \mathbf{Q}_{1} \mathbf{u}+\overline{\mathbf{u}}_{\mathrm{H}}^{\prime} \mathbf{Q}_{1} \overline{\mathbf{u}}_{\mathrm{H}}\right]$ \\
\hline$\gamma_{3,2}=\frac{2}{N} E\left[\overline{\mathbf{u}}_{\mathrm{H}}^{\prime} \mathbf{Q}_{1} \overline{\overline{\mathbf{u}}}_{\mathrm{HV}}\right]$ & $\gamma_{4,2}=\frac{1}{N} E\left[\overline{\overline{\mathbf{u}}}_{\mathrm{HV}}^{\prime} \mathbf{Q}_{1} \mathbf{u}+\overline{\mathbf{u}}_{\mathrm{H}}^{\prime} \mathbf{Q}_{1} \overline{\mathbf{u}}_{\mathrm{V}}\right]$ \\
\hline$\gamma_{3,3}=-\frac{1}{N} E\left[\overline{\overline{\mathbf{u}}}_{\mathrm{H}}^{\prime} \mathbf{Q}_{1} \overline{\overline{\mathbf{u}}}_{\mathrm{H}}\right]$ & $\gamma_{4,3}=-\frac{1}{N} E\left[\overline{\overline{\mathbf{u}}}_{\mathrm{H}}^{\prime} \mathbf{Q}_{1} \overline{\mathbf{u}}_{\mathrm{H}}\right]$ \\
\hline$\gamma_{3,4}=-\frac{1}{N} E\left[\overline{\overline{\mathbf{u}}}_{\mathrm{HV}}^{\prime} \mathbf{Q}_{1} \overline{\overline{\mathbf{u}}}_{\mathrm{HV}}\right]$ & $\gamma_{4,4}=-\frac{1}{N} E\left[\overline{\overline{\mathbf{u}}}_{\mathrm{HV}}^{\prime} \mathbf{Q}_{1} \overline{\mathbf{u}}_{\mathrm{V}}\right]$ \\
\hline$\gamma_{3,5}=-\frac{2}{N} E\left[\overline{\overline{\mathbf{u}}}_{\mathrm{H}}^{\prime} \mathbf{Q}_{1} \overline{\overline{\mathbf{u}}}_{\mathrm{HV}}\right]$ & $\gamma_{4,5}=-\frac{1}{N} E\left[\overline{\overline{\mathbf{u}}}_{\mathrm{HV}}^{\prime} \mathbf{Q}_{1} \overline{\mathbf{u}}_{\mathrm{H}}+\overline{\overline{\mathbf{u}}}_{\mathrm{H}}^{\prime} \mathbf{Q}_{1} \overline{\mathbf{u}}_{\mathrm{V}}\right]$ \\
\hline$\gamma_{3,6}=0$ & $\gamma_{4,6}=0$ \\
\hline$\gamma_{3,7}=\frac{1}{N} \operatorname{tr}\left(\mathbf{H}^{\prime} \mathbf{H}\right)$ & $\gamma_{4,7}=0$ \\
\hline Moment condition $\mathrm{M}_{3, \mathrm{~V}}$ (row 7) & Moment condition $\mathrm{M}_{4, \mathrm{~V}}$ (row 8) \\
\hline$\gamma_{7}=\frac{1}{N} E\left[\overline{\mathbf{u}}_{\mathrm{V}}^{\prime} \mathbf{Q}_{1} \overline{\mathbf{u}}_{\mathrm{V}}\right]$ & $\gamma_{8}=\frac{1}{N} E\left[\overline{\mathbf{u}}_{\mathrm{V}}^{\prime} \mathbf{Q}_{1, N} \mathbf{u}\right]$ \\
\hline$\gamma_{7,1}=\frac{2}{N} E\left[\overline{\mathbf{u}}_{\mathrm{V}}^{\prime} \mathbf{Q}_{1} \overline{\overline{\mathbf{u}}}_{\mathrm{VH}}\right]$ & $\gamma_{8,1}=\frac{1}{N} E\left[\overline{\overline{\mathbf{u}}}_{\mathrm{VH}}^{\prime} \mathbf{Q}_{1} \mathbf{u}+\overline{\mathbf{u}}_{\mathrm{V}}^{\prime} \mathbf{Q}_{1} \overline{\mathbf{u}}_{\mathrm{H}}\right]$ \\
\hline$\gamma_{7,2}=\frac{2}{N} E\left[\overline{\mathbf{u}}_{\mathrm{V}}^{\prime} \mathbf{Q}_{1} \overline{\overline{\mathbf{u}}}_{\mathrm{V}}\right]$ & $\gamma_{8,2}=\frac{1}{N} E\left[\overline{\overline{\mathbf{u}}}_{\mathrm{V}}^{\prime} \mathbf{Q}_{1} \mathbf{u}+\overline{\mathbf{u}}_{\mathrm{V}}^{\prime} \mathbf{Q}_{1} \overline{\mathbf{u}}_{\mathrm{V}}\right]$ \\
\hline$\gamma_{7,3}=-\frac{1}{N} E\left[\overline{\overline{\mathbf{u}}}_{\mathrm{VH}}^{\prime} \mathbf{Q}_{1} \overline{\overline{\mathbf{u}}}_{\mathrm{VH}}\right]$ & $\gamma_{8,3}=-\frac{1}{N} E\left[\overline{\overline{\mathbf{u}}}_{\mathrm{VH}}^{\prime} \mathbf{Q}_{1} \overline{\mathbf{u}}_{\mathrm{H}}\right]$ \\
\hline$\gamma_{7,4}=-\frac{1}{N} E\left[\overline{\overline{\mathbf{u}}}_{\mathrm{V}}^{\prime} \mathbf{Q}_{1} \overline{\overline{\mathbf{u}}}_{\mathrm{V}}\right]$ & $\gamma_{8,4}=-\frac{1}{N} E\left[\overline{\overline{\mathbf{u}}}_{\mathrm{V}}^{\prime} \mathbf{Q}_{1} \overline{\mathbf{u}}_{\mathrm{V}}\right]$ \\
\hline$\gamma_{7,5}=-\frac{2}{N} E\left[\overline{\overline{\mathbf{u}}}_{\mathrm{VH}}^{\prime} \mathbf{Q}_{1} \overline{\overline{\mathbf{u}}}_{\mathrm{V}}\right]$ & $\gamma_{8,5}=-\frac{1}{N} E\left[\overline{\overline{\mathbf{u}}}_{\mathrm{V}}^{\prime} \mathbf{Q}_{1} \overline{\mathbf{u}}_{\mathrm{H}}+\overline{\overline{\mathbf{u}}}_{\mathrm{VH}}^{\prime} \mathbf{Q}_{1} \overline{\mathbf{u}}_{\mathrm{V}}\right]$ \\
\hline$\gamma_{7,6}=0$ & $\gamma_{8,6}=0$ \\
\hline$\gamma_{7,7}=\frac{1}{N} \operatorname{tr}\left(\mathbf{V}^{\prime} \mathbf{V}\right)$ & $\gamma_{8,7}=0$ \\
\hline
\end{tabular}


Table A (continued). Definition of the elements of $\gamma$ and $\boldsymbol{\Gamma}$ in equation system (A.17)

\begin{tabular}{rlrl}
\hline Moment condition $\mathbf{M}_{\mathrm{a}}($ row 9$)$ & Moment condition $\mathrm{M}_{\mathrm{b}}($ row 10$)$ \\
\hline$\gamma_{9}=\frac{1}{N(T-1)} E\left[\mathbf{u}^{\prime} \mathbf{Q}_{0} \mathbf{u}\right]$, & $\gamma_{10}=\frac{1}{N(T-1)} E\left[\mathbf{u}^{\prime} \mathbf{Q}_{1} \mathbf{u}\right]$ \\
$\gamma_{9,1}=\frac{2}{N(T-1)} E\left[\overline{\mathbf{u}}_{\mathrm{H}}^{\prime} \mathbf{Q}_{0} \mathbf{u}\right]$ & $\gamma_{10,1}=\frac{2}{N} E\left[\overline{\mathbf{u}}_{\mathrm{H}}^{\prime} \mathbf{Q}_{1} \mathbf{u}\right]$ \\
$\gamma_{9,2}=\frac{2}{N(T-1)} E\left[\overline{\mathbf{u}}_{\mathrm{V}}^{\prime} \mathbf{Q}_{0} \mathbf{u}\right]$ & $\gamma_{10,2}=\frac{2}{N} E\left[\overline{\mathbf{u}}_{\mathrm{V}}^{\prime} \mathbf{Q}_{1} \mathbf{u}\right]$ \\
$\gamma_{9,3}=-\frac{1}{N(T-1)} E\left[\overline{\mathbf{u}}_{\mathrm{H}}^{\prime} \mathbf{Q}_{0} \overline{\mathbf{u}}_{\mathrm{H}}\right]$ & $\gamma_{10,3}=-\frac{1}{N} E\left[\overline{\mathbf{u}}_{\mathrm{H}}^{\prime} \mathbf{Q}_{1} \overline{\mathbf{u}}_{\mathrm{H}}\right]$ \\
$\gamma_{9,4}=-\frac{1}{N(T-1)} E\left[\overline{\mathbf{u}}_{\mathrm{V}}^{\prime} \mathbf{Q}_{0} \overline{\mathbf{u}}_{\mathrm{V}}\right]$ & $\gamma_{10,4}=-\frac{1}{N} E\left[\overline{\mathbf{u}}_{\mathrm{v}}^{\prime} \mathbf{Q}_{1} \overline{\mathbf{u}}_{\mathrm{V}}\right]$ \\
$\gamma_{9,5}=-\frac{2}{N(T-1)} E\left[\overline{\mathbf{u}}_{\mathrm{H}}^{\prime} \mathbf{Q}_{0} \overline{\mathbf{u}}_{\mathrm{V}}\right]$ & $\gamma_{10,5}=-\frac{2}{N} E\left[\overline{\mathbf{u}}_{\mathrm{H}}^{\prime} \mathbf{Q}_{1} \overline{\mathbf{u}}_{\mathrm{V}}\right]$ \\
$\gamma_{9,6}=1$ & $\gamma_{10,6}=0$ \\
$\gamma_{9,7}=0$ & $\gamma_{10,7}=1$ \\
\hline
\end{tabular}

\section{A.1.4 Consistency and optimal weighting}

It follows as a special case of Badinger and Egger (2008), that the GM estimator defined by (A.18) is consistent under fairly general conditions, provided that the elements of $\gamma$ and $\Gamma$ are based on consistent estimates of $\mathbf{u}^{15}$ That is

$$
\left(\tilde{\rho}_{\mathrm{H}}, \tilde{\rho}_{\mathrm{V}}, \tilde{\sigma}_{v}^{2}, \tilde{\sigma}_{1}^{2}\right) \stackrel{P}{\rightarrow}\left(\rho_{\mathrm{H}}, \rho_{\mathrm{V}}, \sigma_{v}^{2}, \sigma_{1}^{2}\right) \text { as } N \rightarrow \infty
$$

This result holds for any weighting matrix $\boldsymbol{\Lambda}$ in (A.18). However, it is well known from the literature on GMM estimation that it is optimal to use the inverse of the (properly normalized) variance covariance matrix of the moment vector, evaluated at the true parameter values, as weight in (A.18). Define the $10 \times 1$ vector $\mathbf{m}$ that includes the left hand side of the moment conditions given in (A.12), (A.14), (A.15), and (A.16) with the expectations operator suppressed. The optimal weighting matrix is then given as

$$
\mathbf{\Lambda}^{o p t}=\left\{N E\left[\mathbf{m m}^{\prime}\right]\right\}^{-1}
$$

\footnotetext{
${ }^{15}$ See Badinger and Egger (2008) for the full set of assumptions required and the proofs.
} 
Notice that the matrix $\Lambda^{\text {opt }}$ is symmetric and of order $10 \times 10$. Its elements are derived by substituting (A.11) and (A.9) into the moment conditions and using the result that $\operatorname{Cov}\left(\boldsymbol{\eta}^{\prime} \mathbf{A} \boldsymbol{\eta}, \boldsymbol{\eta}^{\prime} \mathbf{B} \boldsymbol{\eta}^{\prime}\right)=2 \operatorname{tr}\left(\mathbf{A} \boldsymbol{\Omega}_{\eta} \mathbf{B} \boldsymbol{\Omega}\right)$ for two non-negative definite symmetric matrices $\mathbf{A}$ and $\mathbf{B}$ and $\left.\boldsymbol{\eta} \sim N\left(0, \Omega_{\eta}\right)\right)$ (e.g., Amemiya, 1971, p. 5). The elements are obtained as special case of Badinger and Egger (2008) with $R=2$. For the sake of brevity, we do not report the elements of the weighting matrix here.

Since the optimal weighting matrix $\boldsymbol{\Lambda}^{\text {opt }}$ depends on on $\sigma_{\omega}^{2}$ and $\sigma_{1}^{2}$, initial estimates of the parameters $\rho_{\mathrm{H}}, \rho_{\mathrm{V}}, \sigma_{v}^{2}$ and $\sigma_{\omega}^{2}$ are required. As suggested by Kapoor, Kelejian, and Prucha (2007), these are obtained using a subset of the moment conditions ((A.12), (A.14), (A.15), (A.16)) and the identity matrix as weight in (A.18). ${ }^{16}$

\section{A2. FGLS estimation of model (1)}

Having obtained an estimate of the spatial regressive parameter and the variances of the error components, model (1) can be estimated using a feasible generalized least squares (FGLS) procedure. The true GLS estimator of model (1) is defined as

$$
\hat{\beta}^{G L S}=\left\{\mathbf{X}\left[\mathbf{\Omega}_{u}^{-1}\left(\rho_{\mathrm{H}}, \rho_{\mathrm{V}}, \sigma_{\omega}^{2}, \sigma_{1}^{2}\right)\right] \mathbf{X}\right\}^{-1} \mathbf{X}\left[\mathbf{\Omega}_{u}^{-1}\left(\rho_{\mathrm{H}}, \rho_{\mathrm{V}}, \sigma_{\omega}^{2}, \sigma_{1}^{2}\right)\right] \mathbf{y} .
$$

The feasible generalized least squares (FGLS) estimator is obtained by replacing the true parameters $\rho_{\mathrm{H}}, \rho_{\mathrm{V}}, \sigma_{\omega}^{2}$, and $\sigma_{1}^{2}$ by their estimates. As demonstrated by Kapoor, Kelejian, and Prucha (2007) and by Badinger and Egger (2008) for the higher order case, the GLS and FGLS estimators are asymptotically equivalent. As a consequence $\hat{\beta}_{N}^{F G L S}$ is asymptotically normally distributed under standard assumptions.

\section{Appendix B. Data description}

\section{B1. List of countries and industries}

Our sample is made up of a balanced panel of 2016 observations. The cross-section consists of 16 countries and 7 industries. The time period ranges from 1983 to 2000.

\footnotetext{
${ }^{16}$ Kapoor, Kelejian, and Prucha (2007) show, using a Monte Carlo study, that this 'initial GM estimator' performs better than the alternative to use an unweighted estimation based on all moment conditions in the first step.
} 
The following countries are included: Austria, Belgium (and Luxembourg), Denmark, Finland, France, Germany, Greece, Irland, Italy, Netherlands, Norway, Portugal, Spain, Sweden, Switzerland, United Kingdom.

The following industry classification is used: Food and kindred products (ISIC Rev3: 15-22), Chemicals and allied products (23-26), Basic metals \& fabricated metal products (27-28), Machinery \& equipment, not elsewhere classified (29), Electric and electronic equipment (3033), Transport equipment (34-35), Manufacturing not elsewhere classified (36-37).

\section{B2. Construction of horizontal and vertical Interdependence matrices $\mathbf{H}$ and $\mathbf{V}$}

The cross-section dimension comprises country-industry pairs $i j$, where index $i$ refers to countries and index $j$ to industries. The elements of the matrices $\mathbf{V}=\left[v_{i j, l m}\right]$ and $\mathbf{H}=\left[h_{i j, l m}\right]$ thus reflect vertical and horizontal relations between country i's industry $j$ and country l's industry $m$.

Horizontal linkages are measured by final goods trade between the same industries (in terms of imports or imports plus exports of final goods as share of gross output), i.e.,

$$
h_{i j, l m}=\frac{T_{i j, l m}^{\text {Final }}}{P R O D_{i j}} \text { for } i \neq l \text { and } j=m \text {, and } 0 \text { otherwise. }
$$

Vertical linkages are measured by intermediate goods trade both within and between countries (imports or imports plus exports of intermediaries as share of gross output), i.e.,

$$
v_{i j, l m}=\frac{T_{i j, l m}^{I O}}{P R O D_{i j}} \text {, for } i \neq l \text { or } j \neq m \text {, and } 0 \text { for } i=l \text { and } j=m \text {. }
$$

\section{Horizontal interdependence $(\mathbf{H})$}

Bilateral (international) imports of all goods (intermediate and final) for the countries of our sample by industry are available from the OECD STAN Bilateral Trade Database. These values are total imports from industry $j$ of country $l$ but we there is no information to which domestic industries they are delivered. As an approximation we assume that trade in final goods shows the same pattern as that of domestic I-O flows between industries, i.e., country $i$ 's imports of goods from country $l$ and industry $m$ are assigned to country $i$ 's industries $j$ according to the share that a particular industry $j$ uses from the total deliveries of (domestic) industry $m$ to all other domestic industries. The case relevant here is $j=m$ and $i \neq l$. 


\section{Vertical Interdependence (V)}

Input-output flows within countries are available from the OECD Input-Output Database for each industry pair (domestic use). It also provides information on the imports of intermediaries (international use) for each industry pair, although not by trading partner. As an approximation, imports of intermediate goods from industry $m$ are thus assumed to exhibit the same bilateral pattern as total imports from industry $m .^{17}$ In particular, the level of imported intermediate goods (i.e., international use of intermediates) of country $i$ 's industry $j$ from country l's industry $m$ is obtained by multiplying the total international use of country $i$ 's industry $j$ from all countries' industries $m$ (available from OECD I-O Database) with the share of country i's imports of (intermediate and final) goods coming from country $l$. This approach exploits the country-pair specific variation in total imports and the industry-pair specific variation in intermediate goods use to obtain both country-and industry-pair specific measures of intermediates goods use of country $i$ 's industry $j$ from country l's industry $m$.

This yields two matrices of dimension $I J \times I J$. Define $\mathbf{T}^{\mathrm{M} \text {,Total }}$ as matrix reflecting total imports with nonzero elements only where industry $j=m$ and $i \neq l$, and $\mathbf{T}^{\mathrm{M}, \mathrm{IO}}$ as matrix of the (domestic and international) use of intermediates where all elements could in principle take nonzero values. The main diagonal elements of both matrices are set to zero. Obviously, the matrix $\left(\mathbf{T}^{\mathrm{M}, \text { Total }}-\mathbf{T}^{\mathrm{M}, \mathrm{IO}}\right.$ ), with nonzero elements for industry $j=m, i \neq l$ only, then reflects horizontal imports of final goods $\left(\mathbf{T}^{\mathrm{M}, \text { Final }}\right){ }^{18}$ The corresponding matrices with the levels of exports of final goods $\left(\mathbf{T}^{\mathrm{X}, \text { Final }}\right)$ and domestic and international delivery of intermediate goods $\left(\mathbf{T}^{\mathrm{X}, \mathrm{IO}}\right.$ ) are obtained by taking the transpose of $\mathbf{T}^{\mathrm{M} \text {,Final }}$ and $\mathbf{T}^{\mathrm{M}, \mathrm{IO}}$ respectively. Summing up the import (use) and export (delivery) matrices, i.e., $\mathbf{T}^{\mathrm{MX} \text {,Final }}=\mathbf{T}^{\mathrm{M} \text {,Final }}+\mathbf{T}^{\mathrm{X} \text {,Final }}$ and $\mathbf{T}^{\mathrm{MX}, \mathrm{IO}}=\mathbf{T}^{\mathrm{M}, \mathrm{IO}}+\mathbf{T}^{\mathrm{X}, \mathrm{IO}}$, and expressing each element as share of gross output of country 's industry $j\left(P R O D_{i j}\right)$ yields the (unnormalized) matrices $\mathbf{H}^{0}$ and $\mathbf{V}^{0}$. Finally, the matrices $\mathbf{H}$ and $\mathbf{V}$ are obtained by row-normalizing $\mathbf{H}^{0}$ and $\mathbf{V}^{0}$, i.e.,

\footnotetext{
${ }^{17}$ A similar approach is used by Feenstra and Hanson (1999), who combine data on imports of final goods with data on total input purchases, to obtain a breakdown of imported intermediate inputs by industry for U.S. data. Bergstrand and Egger (2008) provide evidence that at least aggregate trade among the OECD countries in intermediate goods behaves remarkably similar to final goods trade.

${ }^{18}$ Since intermediate goods trade is a substantial share of total trade and since the bilateral approximation is not perfect, some values turned out negative. We regard this as evidence for negligible trade in final goods and set these values to zero.
} 
dividing each element by the respective row sum, i.e. $h_{i j, m l}=h_{i j, m l}^{0} / \sum_{m l} h_{i j, m l}^{0}$ and $v_{i j, m l}=v_{i j, m l}^{0} / \sum_{m l} v_{i j, m l}^{0}$

\section{B3. Descriptive statistics of main variables}

Table B. Descriptive Statistics of Main Variables

\begin{tabular}{lrrrr}
\hline & \multicolumn{1}{c}{ Mean } & Std. Dev. & \multicolumn{1}{c}{ Minimum } & \multicolumn{1}{c}{ Maximum } \\
\hline Foreign affiliate sales & 3708.694 & 9120.316 & 0.002 & 159962.700 \\
Output & 63822.120 & 112650.400 & 158.293 & 1120897.000 \\
Apparent consumption & 61719.800 & 101578.100 & 269.000 & 928142.000 \\
Imports & 0.598 & 0.491 & 0.034 & 5.941 \\
Exports & 0.476 & 0.281 & 0.013 & 2.884 \\
Value added/employment & 20.170 & 20.079 & 0.025 & 224.420 \\
\hline
\end{tabular}

Foreign affiliate sales, output, and apparent consumption are expressed in 1000 US-\$. Imports and exports expressed as fraction of gross output. Value added/employment is expressed in real 1000 US-\$ per employee.

\section{Appendix C. Construction of predicted interdependence matrices $\hat{\mathbf{H}}$ and $\hat{\mathbf{V}}$}

Considering the matrix of horizontal interdependences $\mathbf{H}$ first, the following gravity type model is estimated:

$$
\ln h_{i j, m l}^{0}=\kappa_{i, m}+\eta_{j, l}+\gamma_{j, l} \ln D I S T_{i, m}+\omega_{i j, m l},
$$

where $h_{i j, m l}^{0}$ is an element of the (unnormalized) matrix $\mathbf{H}^{0}$, reflecting international final goods imports plus exports as a share of gross output, $\kappa_{i, m}$ is a set of country-pair dummies $\left(i, m=1, \ldots, 16\right.$ )and $\eta_{j, l}$ is a set of industry-pair dummies $(j, l=1, \ldots, 7) . D I S T_{i, m}$ denotes average distance between countries $i$ and $m$ (or, for $i=m$, internal distance defined as $D I S T_{i, i}=0.67 \sqrt{A R E A_{i} / \pi}$ ); its parameter is allowed to vary across industry-pairs. The data source for distance ( $D I S T_{i, m}$ ) is the CEPII database (see Mayer and Zignago, 2006).

For horizontal interdependences, model in (A.14) is estimated for observations with $j=l$ only. Of the potentially 1680 observations, there are 1358 nonzero entries ${ }^{19}$; the model has

${ }^{19}$ One could avoid losing observations by employing a Poisson quasi-maximum likelihood model as suggested by Santos Silva and Tenreyro (2006). However, the latter obtains very similar effects in our case. 
potentially 254 parameters. With an adjusted $R^{2}$ of 0.748 the model explains a substantial part of the variation in horizontal final goods trade intensity across countries and industries. Hence, model (C.1) serves our purpose well, given our goal to generate exogenous weights from predicted values.

The parameter estimates of model (C.1) are then used to generate the predicted weights matrix as follows:

$$
\hat{h}_{i k, j l}^{0}=\exp \left(\hat{\kappa}_{i, m}+\hat{\eta}_{j, l}+\hat{\gamma}_{j, l} \ln D I S T_{i, m}\right) .^{20}
$$

For observations with a zero entry, the predictions are set to zero as well. The predicted values $\hat{h}_{i m, j l}^{0}$ are then used to set up the unnormalized predicted weights matrix $\hat{\mathbf{H}}^{0}=\left[\hat{h}_{i j, m l}^{0}\right]$, which is row-normalized to obtain the final predicted weights matrix $\hat{\mathbf{H}}$.

The construction of the vertical interdependence matrix $\hat{\mathbf{V}}$ proceeds in the same way. Here, the full set of 12432 nonzero observations is available and the model has potentially 354 parameters. Again the gravity model performs reasonably well with an adjusted $R^{2}$ of 0.888 .

${ }^{20}$ The conditional expectation of $w$ is equal to $\exp \left(\hat{\kappa}_{i, m}+\hat{\eta}_{j, l}+\hat{\gamma}_{j, l} \ln D I S T_{i, k}\right)$ times $E\left[\exp \left(\omega_{i m, j l}\right)\right]$. Under normality $E\left[\exp \left(\omega_{i m, j l}\right)\right]=\exp \left[\left(\sigma_{i m, j l}^{2} / 2\right)\right]$, where $\sigma_{i m, j l}^{2}$ is the variance of $\omega_{i m, j l}$. Since $\omega$ is modelled as homoskedastic, this correction factor is the same for all observations and can be dropped without consequences for the results regarding the final rowstandardized weights matrix. 


\section{CESifo Working Paper Series}

for full list see www.cesifo-group.org/wp

(address: Poschingerstr. 5, 81679 Munich, Germany, office@cesifo.de)

2265 Robert S. Chirinko and Huntley Schaller, The Irreversibility Premium, March 2008

2266 Andrea Galeotti and José Luis Moraga-González, Platform Intermediation in a Market for Differentiated Products, April 2008

2267 Torben M. Andersen and Michael Svarer, The Role of Workfare in Striking a Balance between Incentives and Insurance in the Labour Market, April 2008

2268 Harald Badinger, Cyclical Fiscal Policy, Output Volatility, and Economic Growth, April 2008

2269 Thomas Aronsson and Erkki Koskela, Outsourcing and Optimal Nonlinear Taxation: A Note, April 2008

2270 Gary E. Bolton, Claudia Loebbecke and Axel Ockenfels, How Social Reputation Networks Interact with Competition in Anonymous Online Trading: An Experimental Study, April 2008

2271 Nikolaus Wolf, Scylla and Charybdis. Explaining Europe’s Exit from Gold, January 1928 - December 1936, April 2008

2272 Michael Funke and Marc Gronwald, The Undisclosed Renminbi Basket: Are the Markets Telling us something about where the Renminbi - US Dollar Exchange Rate is Going?, April 2008

2273 Thor Olav Thoresen and Annette Alstadsæter, Shifts in Organizational Form under a Dual Income Tax System, April 2008

2274 Helge Berger and Volker Nitsch, Too many Cooks? Committees in Monetary Policy, April 2008

2275 Yin-Wong Cheung and Eiji Fujii, Deviations from the Law of One Price in Japan, April 2008

2276 Michael S. Michael, Sajal Lahiri and Panos Hatzipanayotou, Integrated Reforms of Indirect Taxes in the Presence of Pollution, April 2008

2277 Bas Jacobs, Is Prescott Right? Welfare State Policies and the Incentives to Work, Learn and Retire, April 2008

2278 Burkhard Heer and Alfred Maußner, Value Function Iteration as a Solution Method for the Ramsey Model, April 2008

2279 Jarko Fidrmuc and Christa Hainz, Integrating with their Feet: Cross-Border Lending at the German-Austrian Border, April 2008 
2280 Kristof Dascher and Alexander Haupt, The Political Economy of Regional Integration Projects at Borders where Rich and Poor Meet: The Role of Cross-Border Shopping and Community Sorting, April 2008

2281 Katrin Assenmacher-Wesche and M. Hashem Pesaran, A VECX* Model of the Swiss Economy, April 2008

2282 Christophe Rault, Robert Sova and Ana Maria Sova, Modeling International Trade Flows between CEEC and OECD Countries, April 2008

2283 Timo Boppart, Josef Falkinger, Volker Grossmann, Ulrich Woitek and Gabriela Wüthrich, Qualifying Religion: The Role of Plural Identities for Educational Production, April 2008

2284 Armin Falk, David Huffman and W. Bentley MacLeod, Institutions and Contract Enforcement, April 2008

2285 Axel Dreher and Stefan Voigt, Does Membership in International Organizations Increase Governments' Credibility? Testing the Effects of Delegating Powers, April 2008

2286 Xavier Freixas and Bruno M. Parigi, Lender of Last Resort and Bank Closure Policy, April 2008

2287 Regina Dionisius, Samuel Muehlemann, Harald Pfeifer, Günter Walden, Felix Wenzelmann and Stefan C. Wolter, Cost and Benefit of Apprenticeship Training - A Comparison of Germany and Switzerland, April 2008

2288 Francesco Daveri and Cecilia Jona-Lasinio, Off-Shoring and Productivity Growth in the Italian Manufacturing Industries, April 2008

2289 Mikael Priks, Do Surveillance Cameras Affect Unruly Behavior? A Close Look at Grandstands, April 2008

2290 Marianna Belloc and Daniela Federici, A Two-Country NATREX Model for the Euro/Dollar, April 2008

2291 Nicolas Treich, The Value of a Statistical Life under Ambiguity Aversion, April 2008

2292 J. Atsu Amegashie, Socially-Tolerable Discrimination, April 2008

2293 M. Hashem Pesaran and Andreas Pick, Forecasting Random Walks Under Drift Instability, April 2008

2294 Steven Brakman, Gus Garita, Harry Garretsen and Charles van Marrewijk, Unlocking the Value of Cross-Border Mergers and Acquisitions, May 2008

2295 Eric O’N. Fisher and Kathryn G. Marshall, The Structure of the American Economy, May 2008 
2296 Claudia M. Buch and Martin Schlotter, Regional Origins of Employment Volatility: Evidence from German States, May 2008

2297 Helmuth Cremer, Philippe De Donder, Dario Maldonado and Pierre Pestieau, Taxing Sin Goods and Subsidizing Health Care, May 2008

2298 Reinhilde Veugelers and Frederick van der Ploeg, Reforming European Universities: Scope for an Evidence-Based Process, May 2008

2299 Jon H. Fiva and Lars J. Kirkebøen, Does the Housing Market React to New Information on School Quality?, May 2008

2300 Tina Klautke and Alfons J. Weichenrieder, Interest Income Tax Evasion, the EU Savings Directive, and Capital Market Effects, May 2008

2301 Harald Badinger and Peter Egger, GM Estimation of Higher Order Spatial Autoregressive Processes in Panel Data Error Component Models, May 2008

2302 Jan K. Brueckner, Slot-Based Approaches to Airport Congestion Management, May 2008

2303 Sören Blomquist, Vidar Christiansen and Luca Micheletto, Public Provision of Private Goods and Nondistortionary Marginal Tax Rates, May 2008

2304 Dan Anderberg and Alessandro Balestrino, The Political Economy of Post-Compulsory Education Policy with Endogenous Credit Constraints, May 2008

2305 Tomer Blumkin, Yoram Margalioth and Efraim Sadka, The Role of Stigma in the Design of Welfare Programs, May 2008

2306 Vesa Kanniainen and Paolo M. Panteghini, Tax Neutrality: Illusion or Reality? The Case of Entrepreneurship, May 2008

2307 Thomas Dohmen, Armin Falk, David Huffman and Uwe Sunde, The Intergenerational Transmission of Risk and Trust Attitudes, May 2008

2308 Guglielmo Maria Caporale and Mario Cerrato, Using Chebyshev Polynomials to Approximate Partial Differential Equations, May 2008

2309 Peter Egger and Doina Maria Radulescu, Labour Taxation and Foreign Direct Investment, May 2008

2310 Laurent Linnemer, Dissipative Advertising Signals Quality even without Repeat Purchases, May 2008

2311 Jordi Jofre-Monseny and Albert Solé-Ollé, Which Communities should be afraid of Mobility? The Effects of Agglomeration Economies on the Sensitivity of Firm Location to Local Taxes, May 2008 
2312 Andreas Haufler and Ferdinand Mittermaier, Unionisation Triggers Tax Incentives to Attract Foreign Direct Investment, May 2008

2313 Ronel Elul and Piero Gottardi, Bankruptcy: Is it enough to Forgive or must we also Forget?, May 2008

2314 Andreas Irmen and Johanna Kuehnel, Productive Government Expenditure and Economic Growth, May 2008

2315 Beate Henschel, Carsten Pohl and Marcel Thum, Demographic Change and Regional Labour Markets: The Case of Eastern Germany, May 2008

2316 Gabriel Felbermayr, Wido Geis and Wilhelm Kohler, Restrictive Immigration Policy in Germany: Pains and Gains Foregone?, May 2008

2317 Michael Hofmann, Gerhard Kempkes and Helmut Seitz, Demographic Change and Public Sector Budgets in a Federal System, May 2008

2318 Paul De Grauwe, Macroeconomic Modeling when Agents are Imperfectly Informed, June 2008

2319 Johann K. Brunner and Susanne Pech, Optimum Taxation of Inheritances, June 2008

2320 Thomas Eichner and Marco Runkel, Corporate Income Taxation of Multinationals in a General Equilibrium Model, June 2008

2321 Rainald Borck and Matthias Wrede, Subsidies for Intracity and Intercity Commuting, June 2008

2322 Patricia Apps and Ray Rees, Testing the Pareto Efficiency of Household Resource Allocations, June 2008

2323 Amihai Glazer, Vesa Kanniainen and Panu Poutvaara, Firms' Ethics, Consumer Boycotts, and Signalling, June 2008

2324 Claudia M. Buch, Jörg Döpke and Kerstin Stahn, Great Moderation at the Firm Level? Unconditional vs. Conditional Output Volatility, June 2008

2325 Helmuth Cremer, Philippe De Donder, Dario Maldonado and Pierre Pestieau, Forced Saving, Redistribution and Nonlinear Social Security Schemes, June 2008

2326 M. Hashem Pesaran and Paolo Zaffaroni, Optimal Asset Allocation with Factor Models for Large Portfolios, June 2008

2327 Harald Badinger and Peter Egger, Horizontal versus Vertical Interdependence in Multinational Activity, June 2008 